\title{
Le Rêve d'un homme ridicule (Fedor Dostoïevski, 1877) adapté par Aleksandr Petrov (1992) : quand l'adaptation devient extrapolation poétique
}

\author{
Jasmine JACQ \\ Université de Franche-Comté
}

« On reconnaît un film de Petrov à la première image », disait en 2006 le cinéaste et documentariste russe S. Mirotchnichenko ${ }^{1}$. Et c'est indubitable. Son style, son trait, d'un point de vue graphique, son travail de la lumière et du mouvement sont sa signature.

Aleksandr Petrov est aujourd'hui reconnu comme l'un des cinéastes d'animation les plus talentueux de sa génération. Il est objectivement d'ailleurs l'un des plus primés, en Russie comme à l'étranger, où ses films (courts, moyens ou longs métrages) ont engrangé entre 1990 et 2017 plus de trente récompenses dans les festivals d'animation les plus prestigieux (Annecy, Espinho, Leipzig, Dresde, Hiroshima, Ottawa...). On ne peut pas ne pas citer d'emblée le prix qui sera celui de sa consécration et situe son niveau de notoriété au plan mondial : l'Oscar du meilleur film d'animation reçu en 2000 pour son adaptation du Vieil Homme et la $\operatorname{Mer}$ (1999, d'après Ernest Hemingway).

1.ČUev, 2006.

Toutes les traductions du russe présentes dans cet article sont celles de l'auteur, exception faite des extraits du Rêve d'un homme ridicule, cités dans la traduction d'André MaRKowicz, 1993. 
SLOVO

306 À l'Est de Pixar : le film d'animation russe et soviétique - nº 48/49

Il importe, avant toute évocation de l'œuvre de Petrov, de faire le détail de sa technique. À l'heure de la numérisation quasi-totale des différentes phases du travail d'animation, Petrov continue en effet à travailler de manière délibérément artisanale, passant maître, au gré du perfectionnement de son art, d'une technique peu répandue $-\mathrm{la}$ «peinture sur verre » (Petrov préfere parler de «peinture animée », de « peinture prenant vie, mouvement »[oživšaja živopis']) $)^{2}$.

Chaque plan est chez lui peint à la main sur un support de verre éclairé. Deux supports sont souvent nécessaires: l'un pour le fond, l'autre pour les personnages. Ils sont ensuite superposés. N'utilisant que rarement pinceaux, baguettes ou chiffons, Petrov façonne la peinture (huiles) et l'image à l'aide de ses seuls doigts, dans un rapport de matérialité directe avec son sujet. Chaque plan est ensuite photographiés.

L'intégralité de l'image n'est pas modifiée d'un plan à l'autre, le fond est souvent maintenu et la modification consistera souvent en un mouvement infime : celui d'une pupille, d'une vague, une pierre tombant dans l'eau - d'où la pertinence du double support. Le maintien des couleurs tout au long du dispositif est un enjeu important. Mais plus important encore est le rôle de la lumière dans son travail. Petrov utilise des peintures à séchage lent permettant une importante réverbération des pigments. Les images sont photographiées humides, dans le but de maximiser cet effet. À raison de 24 images par seconde, plus de 1200 peintures sont nécessaires pour une minute de film (soit plus de 70000 pour une heure..., etc.). Chaque film de Petrov représente par conséquent un travail colossal. Le Vieil Homme et la Mer, son long métrage (1999), lui aura demandé deux années et demie d'un travail quasi quotidien.

La possibilité d'un passage aux nouvelles technologies, susceptibles d'accélérer certaines phases du processus de conception de ses films, a été écartée par Petrov dans les années 1990. Non par esprit d'obstination ou de résistance conservatrice, mais parce qu'il n'a jamais été convaincu de leur intérêt pour son travail. La méticulosité extrême qu'il s'impose dans le dessin de chaque plan permet en effet la naissance d'effets non approchables par ordinateur. L'esthétique de Petrov repose sur la combinaison d'une sensibilité toute particulière, issue de la peinture

2. L'expression de « peinture à la main » [ručnaja zivopis'] est parfois utilisée.

3. Dans un documentaire d'Irina Margolina, Petrov se souvient, amusé, que l'utilisation de ses mains pour dessiner ou peindre est née «de la pauvreté ». Sur le film La Nuit [Noč'], (1984), lui et son ami le cinéaste d'animation Vladimir Petkevič avaient mis au point une technique de dessin au marc de café, par manque d'argent pour acheter de la peinture. Margolina, 2002. 
classique et focalisée sur la lumière, et d'un savant travail préparatoire d'esquisses (sur photographies et images vidéo) en quête de la vraisemblance du mouvement.

En résultent des effets de métamorphoses visuelles uniques, une facture changeante, instable des images, les rendant particulièrement mouvantes et organiques. Dans un paradoxe parfaitement résolu, certaines séquences hyperréalistes créent le trouble de par leur ressemblance avec le réel tandis que textures, dessin et lumière insinuent le spectateur dans une sorte de poétique familière car classique dans sa facture. L'expression de « réalisme lyrique » nous semble très appropriée pour qualifier cette synthèse.

Comme souvent lorsqu'on évoque une carrière a posteriori, le parcours de Petrov semble avoir été linéaire. En 1976, l'adolescent doué qu'il était, à qui il semblait toujours « manquer du papier » pour peindre et dessiner ${ }^{4}$, sort diplômé de l'école d'art de Iaroslavl. Il sera ensuite admis, à la fin des années 1970, au département animation de la faculté des beaux-arts du VGIK ${ }^{5}$ à Moscou, où il achèvera brillamment ses études en 1982 (classe d'Ivanov-Vano).

Il fait ses débuts comme illustrateur et metteur en scène aux studios Armenfilms de Erevan en 1981-1982, puis exercera dix années durant au sein des célèbres studios de cinéma et d'animation de Sverdlovsk ${ }^{6}$. En 1988, il sera finalement diplômé du département de mise en scène d'animation des fameux Cours supérieurs de scénario et de mise en scène de $\mathrm{Moscou}^{7}$ (classe de Fedor Khitrouk et de Garri Bardine).

Après avoir été illustrateur de nombreux films, comme ceux de A. Karaïev, V. Petkevitch, V. Fomine ou d'autres figures importantes du paysage de l'animation russe, c'est à ce moment-là, à l'issue des Cours supérieurs, qu'il débutera en tant que metteur en scène de ses propres films. Il prendra désormais en charge scénario, animation et réalisation, et c'est cette triple combinaison qui permettra la pleine révélation de son talent.

Petrov, lorsqu'on l'écoute ou le lit, donne quant à lui au contraire l'impression d'avoir suivi un chemin aléatoire, inconscient, qui ne s'est dessiné que derrière lui. Il se souvient par exemple s'être davantage projeté, au VGIK, dans une carrière de

4. Margolina, 2002.

5.Le prestigieux Institut d'État russe de la cinématographie [Vserossijskij gosudarstvennyj institut kinematografii].

6. Nom, de 1924 à 1991, de la ville de Ekaterinbourg.

7. Vysšie kursy scenaristov i režissërov. Cursus supérieur de perfectionnement de haut niveau en études cinématographiques (cycle de deux ans) créé en 1963 et aujourd'hui placé sous l'égide du ministère de la Culture et de l'Union des cinéastes de Russie. 
SLOVO

308 À l'Est de Pixar : le film d'animation russe et soviétique - no 48/49

graphiste $^{8}$ (Dolgopiat, 2001) et reconnaît à l'envi combien les années passées aux studios de Sverdlovsk, puis aux cours supérieurs ont été déterminants dans son cheminement (Dolgopiat, 2001).

Son talent se révèle dans la décennie 1990. En 1989, La Vache, son film de fin d'études aux Cours supérieurs, une adaptation de Platonov, lui vaut d'emblée une première nomination aux Oscars, quatre prix à l'étranger et un prix en Russie. Le Rêve d'un homme ridicule (1992), autre adaptation et objet de cet article, est récompensé par onze jurys. Puis ce seront La Sirène (1996, sept fois primé), Le Vieil Homme et la Mer (2000, neuf prix dont l'Oscar déjà évoqué du meilleur film d'animation), Mon Amour (2006, neuf prix)...

En dépit de ce parcours brillant, véritable percée au plus haut niveau de son art jusqu'au milieu des années 2000, il émane aujourd'hui encore de cet artiste une infinie simplicité, sorte de modestie naturelle dont témoigne son absence totale de pose intellectuelle. Petrov incarne pleinement un milieu artistique et intellectuel russe tout à la fois exigeant, visant l'excellence, mais également simple, abordable et éminemment collaboratif. Le cinéaste donne de nombreuses master class, a créé sa propre école, prône l'échange, le dialogue simple, l'accessibilité des artistes aux étudiants. Il décrit chaleureusement combien il doit à ses enseignants de Iaroslavl tout d'abord, puis du VGIK, au vieil Ivanov-Vano...

Après Moscou, Erevan et Sverdlovsk, Petrov a rejoint son port d'attache, Iaroslavl, en 1992. Il parvient cette année-là à ouvrir son propre studio, malgré les difficultés. Mis à part une parenthèse de deux ans et demi entre 1996 et 1999 qui l'amena à travailler à Montréal ${ }^{9}$, il a peu quitté cette ville qui est la sienne ${ }^{10}$ et dont il dit aimer l'atmosphère de permanence, la présence du passé, tout ce que les Russes expriment dans le terme de «starina ». Il revendique cet ancrage par la nécessité de ressentir la vie russe, une forme de tranquillité en harmonie avec son identité ${ }^{11}$.

Petrov est croyant - une donnée significative pour la compréhension de son œuvre. Non seulement ses films sont empreints d'une spiritualité profonde, mais son rapport à la création apparaît, au gré des rares interviews qu'il donne, comme intrinsèquement lié à ses convictions orthodoxes. Nombreuses sont les fois où

\section{Petrov, 2001.}

9.Le Canada (consortium Canada/Russie/Japon) lui offrira à l'époque les conditions matérielles nécessaires à son travail sur Le Vieil Homme et la Mer, son premier et seul long métrage, en format IMAX.

10. Petrov est né en 1957 dans le village de Prečistoe, à une centaine de kilomètres au nord de Iaroslavl.

11. Margolina, 2002. 
il répète l'importance d'une « nécessité » (le terme est récurrent) pour peindre, celle de la «sincérité », ou le devoir absolu de ne pas être «faux » [ne fal'sivivit'], qualités qui ne sont pas sans rappeler le cheminement spirituel préparatoire des peintres d'icônes en Russie. Il semble que Petrov perçoive son œuvre dans une dimension profonde de vocation, au sens russe du terme de «prédestination » [prednaznačenie].

D'un naturel modeste - teinté d'austérité diront certains -, cette dimension spirituelle est un aspect qu'il revendique pour ses films, comme il l'exprime en 2010 :

Je ne fais pas des films de divertissement. Je ne fais pas de films drôles. Mes films, c'est comme ça, sont tristes et contiennent des choses que les enfants ou le spectateur moyen, en attente d'effets, ne comprennent pas. Ce sont des films sur l'amour, la fidélité, la loyauté, le péché, la rédemption... Ce sont les choses qui me préoccupent le plus ${ }^{12}$.

Tous les films de Petrov sont, sans exception, inspirés d'œuvres littéraires, et sa prédilection pour les thématiques spirituelles est également perceptible dans le choix des auteurs et des œuvres qui nourrissent son cinéma. Ainsi, dans La Vache (1989), « il n'y a pas de symbolique chrétienne concrète, écrit N. Ermilova, mais il y a un profond message intérieur. Au sens large, c'est un récit sur le sacrifice. ${ }^{13} \gg$ Dans La Sirène (indirectement inspiré de La Pauvre Lise, de Nikolaï Karamzine), on reconnaît le starets du Père Serge de Lev Tolstoï, on est là encore dans le thème du sacrifice pour la foi, de la résignation, du pardon. Le Rêve d'un homme ridicule représente quant à lui un récit analysé comme une forme de couronnement des questionnements philosophiques, religieux et moraux de Dostoïevski. Petrov n'évoque jamais ouvertement son rapport à la foi. Tout au plus se contente-t-il de mentionner, ça et là, ses conversations avec les moines de sa paroisse, ou s'arrête-t-il soudain de parler, songeur, au son du carillon du Kremlin à Iaroslavl ${ }^{14}$.

Le spécialiste de cinéma Alekseï Orlov évoque plus largement l'« humanité infinie » présente dans tous ses films et leur profonde imprégnation avec la vie russe : «Toute la vie russe est là, explique-t-il : on la ressent, profondément...

12. ČUev, 2006.

13. Ermilova \& Voronova, 2003.

14. Margolina, 2002. 
SLOVO

310 À l'Est de Pixar : le film d'animation russe et soviétique - no 48/49

irrationnelle par nature ${ }^{15} \gg$. Nous sommes quoi qu' il en soit avec Petrov devant une cinématographie éminemment singulière.

\section{Le Rêve d'un homme ridicule (1992) ${ }^{16}$ : genèse du projet et rappels thématiques}

Au début des années 1990, Petrov décide d'adapter Le Rêve d'un homme ridicule, nouvelle de Dostoïevski publiée en 1877 dans la seconde partie de son Journal ${ }^{17}$. Ce film, d'une vingtaine de minutes, au souffle narratif puissant, est son second projet individuel abouti. Il va marquer la première partie de son œuvre, et sceller sa reconnaissance.

L'animation russe a beaucoup emprunté au patrimoine littéraire classique $\mathrm{au} \mathrm{XX}^{\mathrm{e}}$ siècle, sous forme de références directes, d'emprunts, d'évocations, de réminiscences ou d'esthétiques particulières. Comme au cinéma, il s'agissait d'un phénomène spontané, renforcé par une culture soviétique très attachée à la mise en valeur du patrimoine littéraire national ${ }^{18}$.

Dostoïevski est néanmoins quasi absent de la production d'animation, comme du cinéma soviétique dans son ensemble, faisant partie des grands auteurs classiques les moins adaptés à l'écran ${ }^{19}$. D'une part, la dimension religieuse de ses romans et sa critique virulente du socialisme comme de l'athéisme ne convenaient pas, on le sait, au pouvoir soviétique, qui a largement compliqué l'accès à ses œuvres comme à leurs rappels dans la culture dès les années 1920. D’autre part, les thématiques dostoïevskiennes, intellectuelles et complexes, n'avaient pas leur place dans les productions enfantines animées, contrairement à celles de Gogol par exemple, dont

\section{5. ČuEv, 2006.}

16. Film disponible en ligneàl'adresse $:$ https://www.youtube.com/watch?v=QspwJ1U1k9Y. 17.Le «Journal» de Dostoïevski, plus tard connu sous l'appellation de Journal d'un écrivain, rassemble un ensemble de textes rédigés entre 1873 et 1881 et conçus dès l'origine pour être publiés. Loin de constituer un «journal intime », il témoigne de l'activité de l'auteur en tant que publiciste et de son intérêt pour les événements contemporains de son temps. Outre les réflexions de l'auteur, le Journal d'un écrivain contient plusieurs œuvres littéraires de fiction, principalement des nouvelles, dont Le Rêve d'un homme ridicule, mais aussi Douce, Bobok, Le Centenaire, Le Moujik Marë̈, et Le Petit Garçon à l'arbre de Noël du Christ.

18. Cf. ŠAtina \& Antropov, qui recense par auteur l'ensemble des œuvres littéraires russes portées à l'écran en Russie/URSS, animation incluse.

19. La revue française CinémAction recense trente-et-un films inspirés de ses œuvres en 2017. ESTÈVE \& LABARRÈRE, 2017. 
l'univers fantastique des œuvres de jeunesse convenait au jeune public et permettait une grande inventivité dans le travail de mise en images. D'un point de vue purement formel et pragmatique enfin, ses œuvres, parcourues d'introspections, de digressions, polyphoniques, sont longues et difficiles à convertir en scénario sur le plan narratif. Petrov s'attèle donc à un matériau complexe et vient nourrir avec son film le retour d'une dialectique rompue avec l'auteur, qui se réamorce précisément dans les années $1990^{20}$.

Petrov avait déjà eu le projet d'adapter une des œuvres de l'auteur dans les années 1980. Tout du moins partiellement, puisqu'il s'agissait de la « Légende du Grand Inquisiteur », célèbre récit philosophique présent dans la seconde partie des Frères Karamazov (1879). Des esquisses avaient été dessinées, un travail commencé. Mais l'insuffisance de dynamique narrative l'avait, dit-il, conduit à renoncer, également conseillé dans ce sens par Youri Norstein.

«La Légende du Grand Inquisiteur » commence de manière captivante, intéressante: l'Espagne, le $\mathrm{XVI}^{\mathrm{e}}$ siècle, les hérétiques, l'Inquisition, les bûchers et tout ce qui s'ensuit. Une époque sombre où se rencontrent un grand inquisiteur et le Christ, revenu sur Terre. Cependant, un dialogue assez complexe intervient ensuite, il ne s'agit pas même d'un dialogue, mais d'un monologue. Le Christ ne dit pas un mot, c'est le grand inquisiteur qui parle. Sur le plan littéraire cela se fait de manière brillante, avec un grand sens de l'intrigue, de la puissance, une douleur aiguë sensible dans les pensées du narrateur. Mais créer une action à partir de cela est chose très complexe. Ce matériau se prête difficilement à une conversion dans le langage du cinéma. J'ai demandé conseil à Youri Norstein. Lui aussi m'a parlé d'une absence de dynamisme de l'action. Cela le dérangeait également. Un film ne peut pas être un inventaire de faits historiques, il doit être plein de vie, quelque chose doit se passer, un kaléidoscope de motifs et d'images. Et si elles n'apparaissent pas, si cette petite flamme ne jaillit pas à la lecture, alors mieux vaut s'arrêter ${ }^{21}$.

Le Rêve d'un homme ridicule lui a paru présenter les caractéristiques narratives nécessaires au transfert du texte à l'image :

20. Mentionnons pour l'animation le film de Nina Šorina, Le Rêve [Son] (1988), librement inspiré de ses œuvres ainsi que de celles de Turgenev et Gončarov. A. Petrov est présent au générique.

21. Petrov, 2001. 
SLOVO

312 À l'Est de Pixar : le film d'animation russe et soviétique - nº 48/49

Le Rêve d'un homme ridicule est un récit assez dynamique sur le plan interne, il rassemble à la fois intrigue, action, autant d'éléments qu'il est possible de représenter. Plusieurs scènes se succèdent, qui fonctionnent sur un plan purement visuel. Elles sont écrites, et l'on peut immédiatement se les représenter ${ }^{22}$.

Surtout, alors que Petrov décrit avoir besoin d'un «choc » pour faire un film ${ }^{23}$ et de la nécessité d'un processus cathartique le liant à l'œuvre, la nouvelle semble avoir produit sur lui un effet sans retour : « [Dostoïevski provoque] des mises en scène violentes dans mon âme ${ }^{24}$ », affirme Petrov, qui a renoncé plusieurs fois à ce projet avant de s'y atteler réellement. Ses hésitations sont d'ordre moral, spirituel, liées à la force intérieure nécessaire au projet et à la volonté de ne pas trahir ou dévoyer l'essence du texte. Il est même rétrospectivement explicite quant au fait qu'il renoncerait aujourd'hui à cette initiative :

Je ne m'attèlerais plus aujourd'hui à un projet pareil. Il faut un âge donné, et un concours de circonstances probablement, pour se lancer dans une telle aventure. Parce que cela vous demande d'aller scruter les confins de votre âme. C'est un auteur qui vous amène à être parfois violent, cynique avec vous-même, à vous tordre les viscères pour comprendre de quoi vous êtes fait, et où est la vérité dans tout ça ${ }^{25} \ldots$

Concernant le récit lui-même, Le Rêve d'un homme ridicule porte le même sous-titre que La Douce (1876), « récit fantastique », lors de sa parution, ce qui, comme le rappelle André Markowicz dans sa note précédant sa traduction en français de la nouvelle dans l'édition des œuvres complètes de 2005, « le rattache à la tradition de La Dame de pique de Pouchkine ou des Récits pétersbourgeois de Gogol, sans parler des nouvelles d'Edgar Poe, que Dostoïevski avait lues et relues dans la traduction de Baudelaire [...] et de celles de Hoffmann ${ }^{26} \gg$.

Cependant, si le fantastique chez Gogol renvoie directement à la notion d'irréalité et de folie, comme le rappelle le grand spécialiste de Dostoïevski,

22. Ibid.

23. MARgolina, 2002.

24.Ibid.

25.Ibid.

26. MARKOWICZ, dans son avant-propos à sa traduction de la nouvelle, in Dostö̈Evski, 2005 , p. 744 . 
Konstantin Motchoulski, dans cette nouvelle, «le fantastique n'est pas dans la forme, il est dans le contenu ${ }^{27} \gg$.

Factuellement, l'intrigue tient en quelques lignes : un soir d'hiver, dans la Russie de la fin du XIX ${ }^{\mathrm{e}}$ siècle, un homme, personnage principal de la nouvelle qui nous livre son récit, décide d'en finir. Il a programmé son suicide. Acheté une arme. La vision d'une étoile par-delà les nuages hostiles lui indique qu' il accomplira son geste le soir même. Chemin faisant vers son meublé, sous la pluie froide de novembre, il fait la rencontre d'une petite fille, grelottante et en haillons, qui implore son aide : sa mère se meurt, quelque chose de tragique est en train d'arriver. L'homme reste néanmoins imperturbable et refoule l'enfant. Obnubilé par son projet de mettre fin à ses jours, l'idée de lui porter secours (le lecteur l'apprendra plus tard) lui paraît incohérente, illogique, insensée puisque comme il le répète sous la forme d'une formule qu'il semble scander à son propre entendement: «Tout lui égal ». Arrivé chez lui, l'arme à la main, le souvenir de la petite lui revient néanmoins, comme ne pouvant s'effacer - obsédant. Harassé par ses pensées et faute de se tuer - il s'endort.
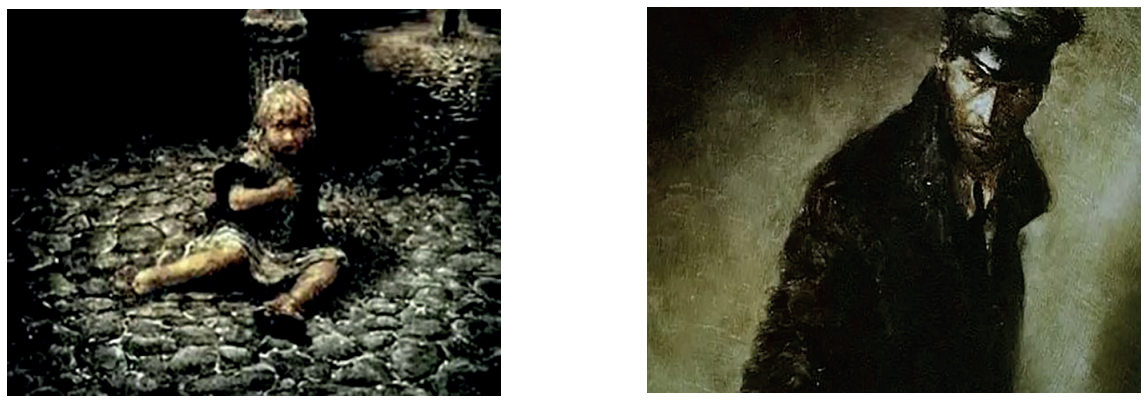

Le Rêve d'un homme ridicule, Aleksandr Petrov, Studios Panorama, 1993, 3'00 et 3'08, captures d'écran

Son sommeil le plonge dans un rêve qui constitue le centre de la nouvelle. La dimension fantastique du récit débute ici. L'homme se représente à lui-même allongé dans sa tombe, après avoir été enterré. Il ressent et perçoit. Une goutte s'écrase à intervalles sur sa paupière gauche. Puis, doucement, comme en flottement, et accompagné d'une sorte de présence, son corps rejoint les airs dans la nuit noire et s'achemine vers un autre astre, une planète dont il reconnaît rapidement les contours puisqu'il s'agit d'une réplique de la Terre. Il s'y achemine et y découvrira l'existence - et donc la possibilité - de la fraternité humaine. Cette Terre n'est pas décrite comme le Paradis au sens chrétien du terme par Dostoïevski. Le lecteur se trouve plongé dans une description de l'Âge d'or, d'une Terre qui n'aurait pas 
SLOVO

314 À l'Est de Pixar : le film d'animation russe et soviétique - nº 48/49

été touchée par le péché, où tous les êtres, hommes, femmes, enfants, vieillards, animaux vivent dans un état d'osmose collective et bienveillante, d'amour mutuel. Le texte convoque la Grèce du mythe, le soleil y est caressant, la mer d'émeraude. Le récit nous plonge au cœur d'une expérience extatique, inspirée par le rêve d'une harmonie universelle.

Comme l'écrit le grand spécialiste de Dostoïevski, Konstantin Motchoulski :

Dans toutes ses œuvres et jusqu'aux Karamazov, on entend la mélodie des chants paradisiaques. Mais cette mélodie n'est nulle part aussi solennelle que dans Le Rêve d'un homme ridicule. [...] Avec une douceur attendrie, l'«homme ridicule» parle des hommes « vraiment beaux » : ils ont de la vie une connaissance supérieure, ils comprennent le langage des animaux et des arbres : leurs âmes sont en contact avec les étoiles, ils s'aiment les uns les autres d'un amour inépuisable ${ }^{28}$.

Invité à partager l'état de félicité unissant, sur cette terre d'amour, l'ensemble du vivant, le narrateur se décrit froidement comme le grain qui changera dans son rêve ce paradis en enfer - un poison mortel. Sa seule présence insufflera en effet progressivement et comme par contamination progressive (le texte parle de « trichine dégoûtante », d' « atome de peste ») le goût des vices et des péchés aux hommes, la vanité, le ressentiment, la jalousie. La nouvelle décrit un enchaînement apocalyptique de souffrances et de destructions (rejoignant en cela la longue tradition littéraire des rêves eschatologiques) : «J'ai contaminé cette Terre qui, avant moi, vivait heureuse et sans péché ».

Le héros se réveillera de son rêve, touché par la révélation de ce qu'il conçoit comme la Vérité $[$ Istina] : l'harmonie entre les hommes est donc néanmoins possible - le royaume de Dieu sur terre. Obstinément, il consacrera le reste de sa vie au prêche. Il retrouvera la petite fille.

La portée religieuse du texte est centrale. Le lecteur ressent fortement la dimension de révélation qui anime le personnage au sortir de son rêve. Le héros a, de son point de vue, vu et ressenti l'harmonie entre les hommes et le vivant de façon si vraisemblable que tout son rapport au réel va en être modifié et se teinter d'une foi dans la fraternité, l'amour, la bienveillance... Ces qualités seraient d'après lui le lot des hommes sans leur vanité et leur goût pour la destruction. Dostö̈evski réitère ici sa conviction profonde, sa foi en «la réalisation de la communion humaine

28.Ibid., p. 465. 
dans l'amour suivant l'enseignement du Christ ${ }^{29}{ }^{\text {} . ~ L a ~ s y m b o l i q u e ~ d o s t o i ̈ e v s k i e n n e ~}$ est claire : c'est l'image persistante de la petite fille qui lui a sauvé la vie au soir de vouloir la quitter. « La rencontre de ce petit être a inopinément abattu le mur de glace de sa solitude, de son meurtrier "tout est égal". En son cœur s'éveillent la pitié et la douleur. ${ }^{30} \gg \mathrm{La}$ rencontre avec la fillette est l'élément déterminant du récit. La Vérité de la Raison ( «j'existe seul, tout m’est égal donc rien ne peut nourrir un sentiment de pitié envers elle ») se heurte à la Raison du Cœur : « une autre personnalité existe aussi réellement que la mienne ». Tout devait lui être égal au moment de se suicider, mais il a eu pitié. Le doute, la compassion, soudain, ont éloigné son acte.

Outre cette approche spirituelle du texte, quiconque connait l'œuvre de Dostö̈evski sait y déchiffrer une lecture idéologique : Le Rêve d'un homme ridicule est une synthèse, un achèvement dans l'explicitation par Dostoïevski de son rapport à l'Europe, à la civilisation, au socialisme, à l'athéisme, au nihilisme...

L'homme ridicule n'est pas un héros, ni même un personnage, c'est un motif, une figure, une image. Ce prototype créé par Dostoïevski est celui de l'homme européen civilisé, et l'ensemble du récit est en réalité une allégorie du conflit de l'époque portant sur l'identité de la Russie (« doit-elle tendre vers l'Occident ou vers ses racines chrétiennes profondes ? »). Dans le récit, l'homme n'a d'ailleurs pas de nom, il représente la civilisation occidentale elle-même, le produit de l'Idéalisme à travers l'absolutisme de la Raison et de la Conscience.

La civilisation - c'est la démonstration de Dostoïevski dans ce texte - propose l'être humain comme source de vérité unique au mépris de toute spiritualité, confinant à l'absurdité de l'existence humaine. Les réponses pour un tel être ne sont pas dans la foi mais dans la raison. Or seul, il s'appauvrit, se fatigue, et tout lui devient égal. Ce n'est pas cet homme qui est ridicule, mais la civilisation qu'il représente.

Motchoulski comme Bakhtine voient dans ce personnage symbolique l'incarnation du concept philosophique d'idéalisme subjectif:

Après Kant, la philosophie idéaliste aboutit au solipsisme. Et Dieu et le monde ne sont que des fantômes de ma conscience. La vie est un songe, tout n'est qu'une apparence, c'est pourquoi « tout est égal ». [...] L'idéalisme subjectif aboutit au non-être pur : le monde

29.Ibid., p. 467-468. Le thème (l'idée d'une fraternité heureuse) est également présent dans Notes d'hiver sur des impressions d'été (1863).

30.Ibid., p. 464. 
SLOVO

316 À l'Est de Pixar : le film d'animation russe et soviétique - nº 48/49

des phénomènes n'est qu'apparence. Mais, parmi les fantômes, la personnalité elle-même devient fantôme ${ }^{31}$.

L'homme ridicule ${ }^{32}$ est donc à l'image de l'homme européen civilisé tel que Dostoïevski se le représente. Sa personnalité seule intègre toute la réalité du monde, rien n'existe au-delà de sa propre conscience. Il est donc coupable d'empêcher le rapprochement, la communion entre les êtres, comme la civilisation occidentale, matérialiste et athée, se rend coupable de cloisonner et d'éloigner les cultures les unes des autres.

Le récit rejoint par sa force les grands textes-traités de l'auteur que sont Le Discours à Pouchkine (1880), La Légende du grand inquisiteur (1879)... Il traite du destin du peuple russe et de l'idée d'un choix : celui que la Russie veut faire pour elle-même.

\section{L'univers dostoïevskien par Petrov : transcodage et extrapolation poétique}

L'adaptation de Petrov dure 20 minutes et 18 secondes. Le film a été réalisé par les studios de Sverdlovsk en 1992, en collaboration avec le jeune studio Panorama que Petrov venait de fonder à Iaroslavl. Petrov assure pour le film les rôles de réalisateur, scénariste, illustrateur-metteur en scène, et animateur. ${ }^{33}$ Youri Norstein, avec qui Petrov a beaucoup échangé à l'origine du projet, est spécifiquement remercié au générique.

Le court-métrage a obtenu le premier prix dans sa catégorie et le prix spécial de l'ASIFA (Association Internationale du Film d'Animation) au festival international d'Ottawa (Canada) en 1992, le premier prix dans sa catégorie au $16^{\mathrm{e}}$ festival international d'animation «Sinanima' 92 » d'Espinho (Portugal), le prix du meilleur film d'animation au festival international d'animation d'Annecy (France) en 1993, le premier prix au festival international de Stuttgart, ainsi que le premier prix au festival international du film de Tiraspol (Moldavie) en 1994.

\section{Ibid.}

32. Certains ont vu dans cette formulation Dostö̈evski lui-même prêchant, à la fin de sa vie, un message auquel il est seul à croire.

33. Fiche technique complète: scénario, réalisation, dessin: A. Petrov; opérateur: S. Rešëtnikov ; montage : L. Poutjatina ; opérateur son : V. Gerrat ; musique : A. Raskatov ; rédacteur musical : S. Sidel'nikov ; lecture : A. Kajdanovskij ; rédacteur : K. Baršt ; Assistant réalisation : I. Ol'švang: Assistant réalisation 2 : I. Klimova. Production : ViKing LTD. 
Nous l'avons dit, les films de Petrov sont tous, sans aucune exception, inspirés d'œuvres littéraires. Interrogé sur cet aspect de son travail, le cinéaste répond: « Mon esprit génère à lui seul peu de choses. Alors je prends ce qu'il y a déjà, je ne sais pas quoi vous dire... ${ }^{34} \gg$ Cette modestie ne saurait cacher un talent scénaristique hors du commun, et une capacité saisissante à inscrire ses films dans une grande fidélité à l'esprit des œuvres tout en les régénérant d'une créativité très personnelle.

L'expérience de Petrov en matière d'adaptation est déjà importante en 1992. Il a réalisé $L a$ Vache deux ans plus tôt et travaillé sur des matériaux littéraires au VGIK comme aux Cours supérieurs. Il connaît, en grand professionnel de l'écriture scénaristique, les enjeux du transfert du texte à l'image : enjeux de condensation du texte, de restructuration, de déplacements narratifs, de conversions médiatiques...

Loin de toute démarche littérale, il semble que ses travaux précédents l'aient au contraire aguerri à l'idée d'une prise de distance inévitable et recherchée avec l'original : « Ce n'était pas exactement $L a$ Vache de Platonov... » dit-il en évoquant son premier film. «Pour La Sirène, l'histoire de La Pauvre Lise [de Karamzine] s'est ensuite réduite à un épisode minuscule... $\gg^{35}$

Le travail de Petrov consiste à condenser le récit, bien sûr, mais sa finesse se situe dans sa capacité à suggérer les « dits comme les non-dits » du texte dans le langage et les procédés de l'animation (dessin, montage, son, couleurs...). Nous sommes devant une démarche particulièrement fine et érudite de transcodage sémantique d'un texte vers un autre média.

Ici, la tradition russe de l'adaptation «d'après les motifs » [po motivam] (d'ailleurs indiquée au générique) s'exprime pleinement. Il s'agit de porter à l'écran une nouvelle lecture de l'œuvre, distanciée, subjective et libre de toute tentative de comparaison.

\section{Omniprésence de la symbolique dostoïevskienne}

Une donnée est constante au fil du travail de Petrov: dès ses premiers films et jusqu'à ceux des années 2000, le soin qu'il porte au respect de l'univers diégétique des œuvres est immense, qu'il s'agisse de celles de Platonov, de Chméliov, de Karamzine, de Tourgueniev, ou d'Hemingway. On ressent chez Petrov non seulement une connaissance précise de chacune des œuvres adaptées, mais une maîtrise de l'ensemble de l'œuvre de ces auteurs, de leurs univers et de leurs images.

L'adaptation qu'il fait du Rêve d'un homme ridicule est édifiante à cet égard, convoquant dans vingt minutes d'images animées une multitude d'éléments

34. Petrov, 2001.

35. Ibid. 
SLOVO

318 À l'Est de Pixar : le film d'animation russe et soviétique - nº 48/49

absents de la courte nouvelle de 1877, mais disséminés dans l'ensemble de l'œuvre de Dostö̈evski.

M. Bakhtine estimait que le récit constituait une sorte d' «encyclopédie » des grands thèmes dostoïevskiens, plusieurs de ses motifs étant également présents dans le personnage du prince Mychkine, chez Raskolnikov, Stavroguine ou Ivan Karamazov ${ }^{36}$. Au même titre, ce n'est pas le texte de la nouvelle stricto sensu qui est ici porté à l'écran, de nombreux autres éléments de l'œuvre de Dostoïevski sont présents, venant souligner la valeur de synthèse du texte.

Ainsi par exemple, dès les premières minutes du film, une séquence de train nous présente le héros. Le narrateur est représenté conversant avec un voyageur et lui racontant son rêve ${ }^{37}$.

Nul train dans la nouvelle qui se contente d'un «C'était un soir lugubre, le plus lugubre qu'il puisse y avoir. À ce moment-là, à onze heures du soir, je rentrais chez moi [...]. » Cette scène est un ajout narratif de Petrov permettant d'insuffler son rythme au film, et d'introduire grâce à la cadence des wagons et à l'avancée du train une sensation de défilement des images à la conscience, de l'ordre de la réminiscence. Le train reviendra à intervalles dans le film. Sur le plan visuel, le spectacle des corps fatigués, entassés, exténués des passagers endormis nous plonge dans la Russie urbaine de la fin du $\mathrm{XIX}^{\mathrm{e}}$ siècle. Cette séquence rappelle inéluctablement, à qui a lu le roman, la description du compartiment de troisième classe des premières pages de L'Idiot. L'Idiot, ou plus largement le symbole d'innocence et de bonté pure qu'incarne son personnage principal, est présent également à travers le choix de la voix du narrateur dans le film, hésitante et naïe, telle qu'on peut se représenter intérieurement celle de Mychkine à la lecture du roman ${ }^{38}$. La tonalité jaunâtre choisie dans le dessin pour cette séquence pourrait enfin ne pas être anodine si l'on se souvient combien cette couleur est importante dans les romans de Dostö̈evski ${ }^{39}$.

\section{BAKHTine, 1998, p. 214.}

37. Le travail de réorganisation interne du récit dans sa chronologie est important chez Petrov. Le fait de créer un interlocuteur (le passager d'un train) pour son narrateur, permet de rendre audibles via la naissance d'un dialogue certains éléments importants du monologue intérieur de la nouvelle : l'idée que son voyage sera ensuite taxé de « rêve », de « délire », d' « hallucination $\gg \ldots$

38. Des passages choisis de la nouvelle sont lus en voix-over par A. Kajdanovskij.

39. La symbolique des couleurs est très importante dans l'analyse des romans de Dostö̈evski. Le jaune est par exemple dans Crime et Châtiment un symbole récurrent d'épuisement, de dépérissement, de souffrance et de pauvreté, que l'auteur utilise tant dans la description de ses personnages (teint, vêtements) que pour des éléments de décors (ainsi le papier peint de la chambre de Raskolnikov est jaune, comme celui de l'appartement de l'usurière, ou encore du bureau de Porphyre Petrovitch)... 
Autre exemple de présence de l'univers dostö̈evskien dans son film, lorsque notre personnage fuit la petite fille dans une course haletante, il croise dans la pénombre des rues étroites de Pétersbourg passants, marchands, prostituées, ivrognes, cochers grossiers hélant leurs chevaux. Là encore nul détail visuel n'était donné dans la nouvelle, dans laquelle Dostoïevski écrit seulement : «D'un coup, j'ai eu l'idée que si le gaz s'était éteint partout, ç’aurait été plus gai, que le gaz rendait le cœur triste, parce qu'il éclairait tout. » Il s'agit ici d'une figure parfaitement elliptique. « Le gaz rend le cœur triste car il éclaire tout », et c'est ce « tout » que notre personnage ne veut plus voir, ces rues froides, hostiles et sordides que Petrov se charge en revanche de restituer visuellement, soignant les effets rythmiques et sonores. La fuite en avant du personnage nous plonge sans doute possible dans les errances nocturnes de Raskolnikov (Crime et Châtiment), ses descriptions des prostituées, l'ivresse des passants... On entend l'orgue de barbarie, les rires, le bruit. La vie pétersbourgeoise est là, très précisément représentée et rappelant immédiatement les descriptions du roman : la débauche des bas-fonds, leur misère. Une fille décortique des graines de

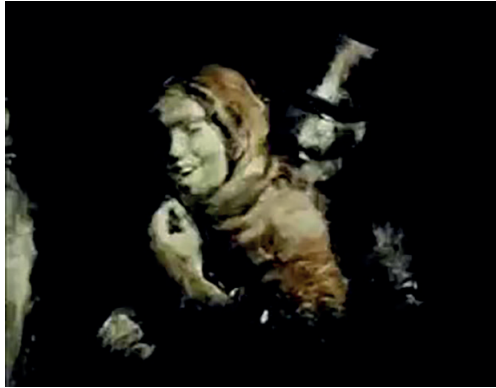

Le Rêve d'un homme ridicule, Aleksandr Petrov, Studios Panorama, 1993, 3'44, capture d'écran tournesol. Les sabots des chevaux heurtent le pavé produisant un effet d'agression auditive (le bruitage est particulièrement surexposé dans la bande-son du film). Deux éléments visuels étaient seulement donnés pour planter l'ensemble de la rencontre avec la fillette dans le récit: une rue déserte et un cocher endormi sur ses drojkis ${ }^{40}$. Petrov transforme cette économie de détails en une exubérance visuelle et sonore capable de faire ressentir à l'écran le sentiment d'aversion et de rejet du narrateur vis-à-vis de la réalité.

Ultime illustration de ce procédé d'utilisation de la symbolique dostö̈evskienne puisée au fil de son œuvre, une araignée vient, quelques minutes plus tard dans le film, courir sur le bras du narrateur. Alors qu'il est arrivé sur l'autre terre et qu'il cherche à séduire naïvement une jeune femme. L'image n'est là encore pas anodine pour qui connaît précisément l'univers dostoïevskien. L'araignée, dans Les Démons, est un symbole suprême du mal : 
SLOVO

320 À l'Est de Pixar : le film d'animation russe et soviétique - nº 48/49

Dansle rêve de Stavroguine, la chute est indiquée symboliquement. Elle n'est marquée que par un signe mystique - une araignée rouge. Dans l'œuvre de Dostoïevski, l'araignée est l'image du principe du mal. Stavroguine écrit dans sa «confession »: « Mais tout à coup, comme au milieu d'une lumière vive, très vive, j'aperçus un point minuscule... Ce point commença soudainement à prendre forme et tout à coup je vis clairement une toute petite araignée rouge $»^{41}$.

L'araignée lui ramène le souvenir de la petite Matriocha violée par lui. Dans le paradis sur terre, le mal pénètre sous l'aspect d'une lubricité meurtrière ${ }^{42}$. Petrov introduit ce symbole de l'arrivée du mal précisément en annonce de l'arrivée du chaos. Il active avec lui, sur un plan mémoriel, l'ensemble du système sémiotique des romans, soulignant encore une fois dans son film la valeur de synthèse de la nouvelle.

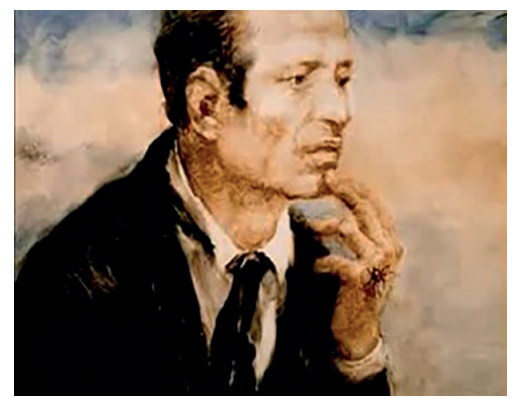

Le Rêve d'un homme ridicule,

Aleksandr Petrov, Studios Panorama, 1993, 13 ' 16 , capture d'écran

\section{Le mouvement des corps au service de la vérité des personnages}

Sur un plan tout à fait distinct, celui du dessin lui-même et du travail d'animation, Aleksandr Orlov estimait dans une interview de 2006 que « les images de Petrov sont presque du cinéma sur le plan de l'énergie de la réception ${ }^{43} \gg$. Une des caractéristiques stylistiques de Petrov tient en effet dans son grand réalisme pictural, une représentation hyperréaliste même du mouvement qui signe ses films. Le réalisme du mouvement des corps est en particulier au cœur de son travail, dès ce second court-métrage.

\section{Motchoulski, 1963, p. 464.}

42. Stavroguine, comme l'« homme ridicule », a, en outrageant une fillette, commis un péché contre la Terre-mère. Mais leur sort est différent : Stavroguine ne se repent pas et périt dans son indifférence cadavérique ; l'« homme ridicule » est sauvé par sa pitié envers celle qu'il a outragée et, après avoir vu en rêve l'âge d'or, il a connu la vérité et il est devenu un autre homme. МотсHOULSKI, 1963, p. 467.

43. ČUEv, 2006. 
On a parfois reproché au cinéaste cette recherche d'une facture proche de l'image cinématographique : «pourquoi dessiner alors ?» Le Rêve d'un homme ridicule nous permet de comprendre ce que recherche Petrov dès ses premiers films: la vraisemblance psychologique des personnages, d'une part (s'agissant d'adaptations), mais, d'autre part, bien au-delà, à travers l'expression physique des corps, une dimension d'universalité, d'humanité partagée exprimée dans le détail et la vraisemblance du mouvement.

Petrov évoque avec plaisir une de ses techniques de prédilection dans la recherche de ce réalisme, l'utilisation de ce qu'il nomme des «prototypes» [prototipy], des «modèles», incarnant physiquement mais aussi spirituellement ses personnages. Très concrètement, au cours du travail préparatoire, naît pour Petrov la nécessité de se représenter mentalement très fortement le personnage. « Le personnage s'oublie très facilement », explique-t-il, « Or je vais devoir le dessiner tant de fois... $\gg^{44}$. Petrov a donc systématisé une technique consistant à choisir, en général dans son entourage proche, des personnes qui vont ensuite incarner son personnage. Il le fait dans une recherche de véracité du mouvement naturel des corps. Il s'agit de les représenter dans leur vérité organique, leur unité physique tout comme spirituelle.

Les deux personnages centraux de la nouvelle sont le narrateur et la petite fille. Réfléchissant à la figuration du narrateur, Petrov avait initialement travaillé sur photographies anciennes, et choisi un fils de la noblesse russe du XIX ${ }^{e}$ siècle. Toutefois, ou bien n'avait-il pas assez de photos, ou bien ne s'était-il pas suffisamment «plongé en lui », mais doucement, il s'est tourné vers un modèle extrêmement proche de lui en la personne de son opérateur, Sergueï Rechetnikov. « C'est un vrai bonheur, que je l'aie vu sous cet angle, alors qu'il est toujours près de moi ! » Des images vidéo ont été tournées avec lui par caméras Éclair, révélant une proximité troublante entre Rechetnikov-modèle, et ce que Petrov recherchait pour le personnage.

Pourquoi ai-je fait cela ? Je ne le sais même pas moi-même [...] Il correspondait en tout: je l'ai vu dans ce costume, sa casquette vissée sur la tête. Il correspondait si bien à l'époque, au visage [du personnage], c'était simplement magnifique, précisément ce qu'il me fallait et le tempérament était le bon. Une heureuse coïncidence en somme... Et Dieu soit loué, il a accepté ! Au début il hésitait, refusait catégoriquement ${ }^{45} \ldots$

44. MARgOLINA, 2002.

45. Dans La Sirène, son fils jouera ce rôle pour « incarner » le jeune moine. Sa belle-mère est présente dans Le Vieil Homme et la Mer. « Je suis à la recherche de modèles, d'inspiration, puis imperceptiblement toujours, quelqu'un s'impose », PETROv, 2001. 
SLOVO

322 À l'Est de Pixar : le film d'animation russe et soviétique - nº 48/49

« À l'origine de la catastrophe tragique, on trouve toujours chez Dostö̈evski l'isolement solipsique de la conscience du héros, son emprisonnement dans son propre univers » écrit Bakhtine ${ }^{46}$. La gestuelle et le visage particulièrement fermé de Rechetnikov, filmés, esquissés, puis mille fois dessinés expriment de manière très convaincante cet isolement du héros de la nouvelle, le repli de son corps comme de sa conscience.

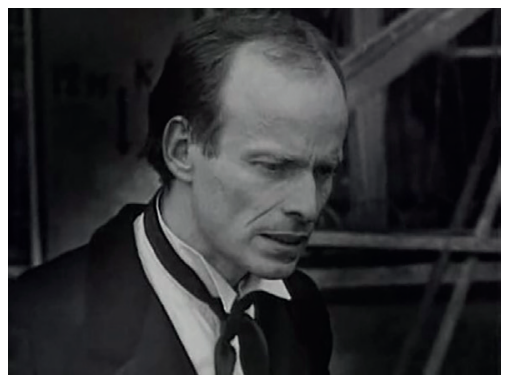

Prototype du personnage

(S. Rechetnikov, son opérateur)

(C) photographie : A. Petrov

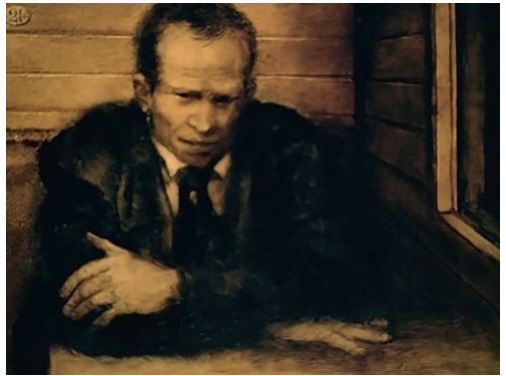

Personnage du narrateur dans les premières minutes du film. Le Rêve d'un homme ridicule, Aleksandr Petrov, Studios Panorama, 1993, 1'43, capture d'écran

Concernant le personnage de la fillette, de nombreuses images vidéos ont là encore été tournées avec une petite fille de Iaroslavl ayant servi de modèle à l'enfant de la nouvelle. La petite fille n'est pas un personnage annexe du récit, ou secondaire, Petrov le sait. Il est central, majeur, essentiel.

La petite fille que l'on offense est une allégorie récurrente chez Dostoïevski. D'une part, elle est l'Innocence, celle de l'Enfance, thème si cher à l'écrivain (L'Idiot). Elle est également une image féminine immanente : « La fillette en pleurs [chez Dostoïevski] est le principe éternellement féminin du monde, l'âme mystique de la terre ${ }^{47} \gg$, écrit Motchoulski.

Deux rêves d'une importance majeure dans l'œuvre de l'écrivain ont en leur centre la présence d'une fillette offensée. Celui de Stavroguine dans Les Démons et celui de Svidrigaillov dans Crime et Châtiment. Rappelons également l'importance du chapitre longtemps impubliable contenant le récit du viol commis par Stavroguine (Les Démons, « la Confession de Stavroguine », ch. 9). L'ensemble des spécialistes de Dostoïevski s'accorde à attribuer au motif de la petite fille dans l'œuvre de l'écrivain une fonction symbolique majeure. Concernant Le Rêve d'un bomme ridicule en particulier et la portée allégorique du personnage de l'enfant,

46. BaKhtine, 1998, p. 40.

47. MotchOULski, 1963, p. 464. 
André Markowicz considère le récit comme une sorte de retournement de «la Confession » : « alors que Stavroguine viole la petite fille et n'en éprouve rien, le héros anonyme du Rêve rejette une petite mendiante parce qu'elle le dérange dans ses pensées suicidaires - et dit, à la toute fin, qu'il a fini par la retrouver. » Il y a ici réconciliation, pardon, paix. Cette nouvelle a en cela un statut très particulier en ce sens que, poursuit Markowicz, «l'indifférence envers la honte, ce centre obscur de l'œuvre de l'écrivain s'est faite pitié et amour ${ }^{48}$. » La petite fille est donc un motif majeur de la nouvelle.

La présence que donne Petrov à cette figure enfantine et féminine est elle aussi centrale, démontrant une fois de plus sa connaissance intime de l'ensemble de l'œuvre de Dostoïevski. La petite fille est représentée une première fois dans la rue, en haillons et suppliante, comme dans la nouvelle, puis elle réapparaît à deux reprises dans des mises en scène imaginées par le cinéaste : courant sur la table dans une autre dimension et invitant le narrateur dans son rêve, puis agenouillée sur le sable, construisant d'étranges châteaux... Ces trois petites filles ont les mêmes traits. Et tout, dans l'expression des mouvements de leurs corps, exprime la douceur, l'enfance, et à travers elles - la permanence du monde. On retrouve trait pour trait dans le dessin et son montage le mouvement des vidéos de Petrov, le mouvement du corps de sa jeune modèle : sa manière de recouvrir pudiquement ses jambes dans le froid, l'engourdissement de son jeune corps...

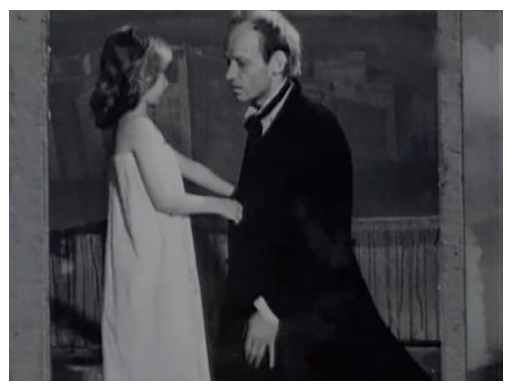

Photographie :

(C) A. Petrov

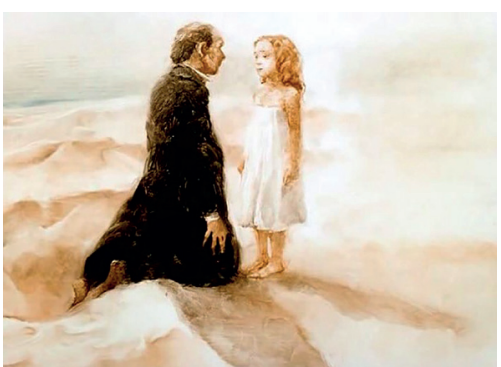

Le Rêve d'un homme ridicule, Aleksandr Petrov, Studios Panorama, 1993, 7’00, capture d'écran

48. DostoḮski, 2005, p. 744. 
SLOVO

324 À l'Est de Pixar : le film d'animation russe et soviétique - no 48/49

Motchoulski écrivait à propos du motif de la petite fille dans la nouvelle :

Le péché de l'idéaliste raisonneur est dans l'offense faite à la Terre-mère. Il s'est détaché de son corps vivant, et cela est crime et suicide. La pitié pour la fillette a été le début du retour au sein maternel : de cette rencontre a jailli, comme une étincelle, la flamme de l'amour pour notre terre, malheureuse, pauvre, mais aimée. Maintenant il connaît la vérité, un bandeau est tombé de ses yeux : il a vu la terre véritable dans sa beauté primordiale, dans son éclat sophique, il a vu l'humanité véritable que le péché n'a pas encore assombrie, il a vu le paradis sur la terre ${ }^{49}$.

Par la précision des mouvements qu'il dessine et anime, Petrov parvient à suggérer l'importance de cette figure. Le réalisme des images, la lenteur du montage créent chez le spectateur une émotion de l'ordre de l'empathie, de la reconnaissance. Cette petite fille est toutes les petites filles : dans ses gestes, mais aussi son élocution, la voix choisie pour elle. Elle convoque un sentiment universel d'humanité et de pitié à la hauteur du message dostoïevskien.

Le reproche d'hyperréalisme adressé à Petrov est donc d'une certaine manière non-avenu. Le but du cinéaste n'est pas la reproduction vraisemblable du réel, du moins au sens d'une gageure esthétique. Il s'agit de créer grâce à des représentations universelles et primitives, détachées du temps et de l'espace, un rapport de reconnaissance intime avec les personnages.

De l'aveu même de Petrov, ajoutons en guise de transition avec les développements qui suivent que sa recherche de réalisme a également pour but une sorte de duperie artistique assumée : nous faire croire au réel, afin de nous emmener vers d'autres dimensions, irréelles et oniriques: « [...] toute la vie réelle que je dessine n'est qu'une sorte de cadre, écrit-il, pour me permettre de montrer mon monde intérieur [fantazija], sans limites [...] ». L'importance qu'il donne au rêve dans ses films est à ce titre capitale. Il précise :

Je m'efforce même, d'un point de vue stylistique, de ne pas opposer rêve et réalité, la réalité que je dessine. Parfois la transition n'est pas perceptible. J'essaie de rendre ce passage invisible dans mes films pour emmener le spectateur sans qu'il s'en rende compte vers un second niveau, d'une certaine manière, pour que cela soit une surprise pour lui. Parfois ça marche, parfois non ${ }^{50}$.

49. DostoÏEsKi, 2005, p. 464-465.

50. Petrov, 2001. 
Petrov serait donc en somme un faux-réaliste, cherchant moins à refléter la réalité qu'à donner au spectateur une «illusion préalable de réalité » pour mieux l'emmener, par processus d'adhésion, vers d'autres sphères, celles des mondes intérieurs, énigmatiques et insondables.

\section{Le rêve : aspect central du processus d'adaptation chez Petrov. Le texte comme matrice}

« Dostoïevski a largement utilisé les possibilités artistiques du rêve, dans presque toutes ses variantes et nuances. On pourrait même dire qu'il n'existe pas dans toute la littérature européenne d'écrivain qui lui ait accordé autant de considération », estime Bakhtine ${ }^{51}$.

Longue et passionnante est à ce titre l'évocation de la place du rêve chez Dostö̈evski. Nous renvoyons le lecteur aux ouvrages d'analyse littéraire sur ce sujet (Meletinski, Bakhtine, Motchoulski). Rappelons simplement, en prolongement des propos de Bakhtine, que tous les romans de Dostoïevski, de Crime et Châtiment à L'Idiot en passant par Les Démons sont habités par des états de demi-sommeil, de fébrilité, de maladie. Dostoïevski, épileptique, connaît les états entourant la perte de conscience. Grande est dans son œuvre la place accordée aux rêves et aux digressions mentales vécues de l'intérieur. Le rêve est souvent chez Dostoïevski le révélateur symbolique des vérités inaccessibles, dont la profondeur psychologique dépasse la connaissance que les personnages ont d'eux-mêmes. Il est l'antithèse de la Raison, comme le rappelle le narrateur du Rêve d'un homme ridicule: « Les rêves, semble-t-il, sont mus non pas par la raison mais par le désir, non par la tête mais par le cœur $[\ldots]^{52} \gg$. Ces oppositions, jugement/désir, esprit/cœur, connaissance/ vérité, sont au centre des conceptions religieuses et du positionnement slavophile de Dostoïevski. Le choix de ce procédé narratif pour la seconde partie de cette nouvelle s'inscrit donc dans une construction intellectuelle et un système symbolique élaborés.

Le rêve constitue un dénominateur commun entre les univers de Dostoïevski et de Petrov. La liberté absolue que permet le dessin sur le plan de la représentation crée l'espace permettant d'accueillir une telle ouvre. En substance, les scènes consacrées au rêve dans le court-métrage donnent l'occasion à Petrov d'un déploiement fantastique de ses propres images, d'un univers référentiel et esthétique particulièrement riche et élaboré.

51.Bakhtine, 1998, p. 212. «Souvenons-nous, ajoute-t-il, des rêves de Rasskolnikov, de Svidrigailov, de Mychkine, d'Hyppolite, de l'Adolescent, de Versilov, d'Aliocha, de D. Karamazov et du rôle qu' ils jouent dans la réalisation idéologique des romans », ibid.

52. Partie II. 
326 À l'Est de Pixar : le film d'animation russe et soviétique - nº 48/49

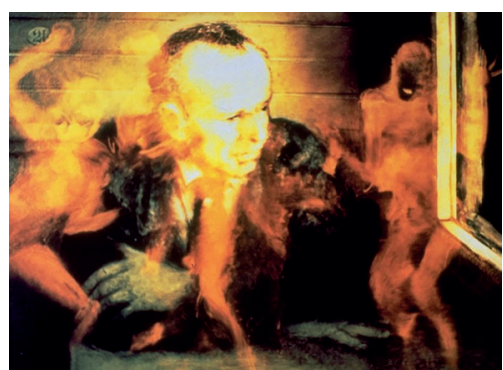

Le Rêve d'un homme ridicule,

Aleksandr Petrov, Studios Panorama, 1993, 2’02, capture d'écran

Le potentiel onirique infini de l'animation a compté dans l'orientation de Petrov. En atteste cet extrait de son échange avec la scénariste et romancière russe Elena Dolgopiat pour la revue Kinovedtcheskie zapiski en 2001 :

$\mathrm{AP}:-$ Je ne sais pas quoi répondre à cela. On m’a déjà posé des questions dans cet esprit, et $\mathrm{j}$ 'inventais des choses, je ne me souviens plus bien de quoi, pour m'en sortir... En réalité, je ne sais pas. Je crée des films non pas pour parler de notre vie réelle, mais pour la transporter dans un univers de rêves. L'amener vers ces zones qu'on ne peut pas filmer avec une caméra, qui doivent prendre forme en pensée, surgir de quelque part. C'est finalement cela la matière de l'animation - ce qui n'existe pas dans la vie ${ }^{53}$.

Les passages consacrés au rêve sont les plus édifiants sur un plan esthétique et expressif dans le film. L'univers symbolique de Petrov se déploie en harmonie profonde avec celui de Dostö̈evski. Les premières minutes du film, le lent mouvement nocturne du train, les images récurrentes de constellations défilant à ses yeux, projettent d'emblée le spectateur dans ce rythme typique de l'approche du sommeil, tandis que la nuit en elle-même l'invite à cette atmosphère de confidence, de confinement et de rêve.

Celui-ci débute à la cinquième minute, alors que le personnage est rentré chez lui, s'est assis à sa table, se préparant à accomplir son acte. À la lumière de sa bougie, il s'agite mentalement, ses pensées sont perturbées par le souvenir de la fillette qu'il a abandonnée à son sort. À l'image, le personnage s'effondre. Un coup de revolver retentit.

La narration glisse vers une autre réalité, fantastique. Le coup de revolver accompagné par un puissant effet sonore, sorte de coup macabre dans la musique de Raskatov nous plonge dans la conscience du héros. Petrov se sent libre de changements narratifs importants : le héros tire dans son cœur alors que le récit de 
Dostoïevski décrit un coup dans la tempe. Toute une iconographie se déploie. Les images nous déportent vers la flamme de la bougie (symbole classique de la mémoire et du passage entre deux réalités), puis la petite fille apparaît soudain courant au

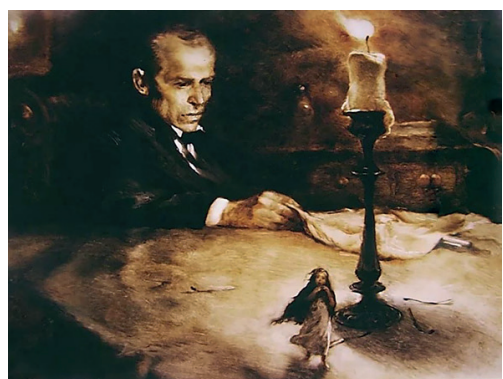

Image de l'affiche du film,

(c) Alexandr Petrov pied du bougeoir, dans une autre dimension. On ne l'entend pas, mais son corps semble appeler notre héros, chercher à le ramener à la scène de leur rencontre. Cet effet, que chacun peut ressentir en rêve, d'abolition des échelles physiques admises, de réductions, de diminutions des formes est présent chez Petrov à plusieurs reprises dans le film. Au même titre que, dans le rêve de Stavroguine, ce qu'il perçoit d'abord comme un point grandit puis devient araignée, la petite

fille s'est ici réduite et court soudain sur la table, emmenant notre héros dans son rêve. La symbolique dostö̈evskienne est là, intacte, restituée par le cinéaste: c'est le souvenir de la petite fille qui sauve le personnage d'accomplir son geste, c'est elle qui le conduit vers la révélation de la Vérité.

Alors que la bande-son évoque une forte accélération et s'impose parmi les autres moyens du film, un personnage apparait, le visage caché par un masque vénitien rouge, au nez protubérant, secoué par un rire gorgé d'alcool. On reconnaît là une figuration du «capitaine » décrit dans la nouvelle, voisin du narrateur organisant de perpétuelles beuveries et terrorisant l'immeuble. Le masque est un motif absent de la nouvelle. Il est néanmoins un leitmotiv d'importance majeure dans le film: il s'agit dans cette

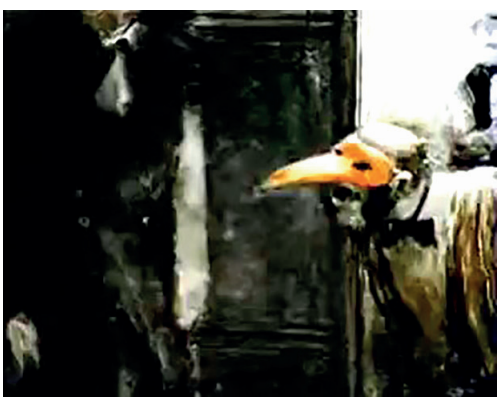

Le Rêve d'un homme ridicule, Aleksandr Petrov, Studios Panorama, 1993, 3'55, capture d'écran scène du célèbre «masque du médecin de peste » ou « masque bec » porté à la Renaissance par les médecins dans le but de ne pas être contaminé par leurs malades. Un autre masque, d'expression froide et ironique, sera ensuite porté par le narrateur sur la «nouvelle Terre » (celle de son rêve), où il représentera le premier signe de tromperie, de mensonge, et finalement ce grain déclencheur du retournement et de la destruction. La présence et la récurrence de masques dans le film constituent un élément de culture carnavalesque particulièrement important, inspiré en droite ligne des analyses bakhtiniennes de Dostoïevski à la fin des années 1920, que nous évoquerons dans la suite de nos développements. 
SLOVO

328 À l'Est de Pixar : le film d'animation russe et soviétique - nº 48/49

Soudain, le film nous projette dans une chute, sorte de descente aux enfers très rapide. Les images défilent non plus horizontalement mais verticalement. La pellicule se transforme ainsi en estampe japonaise, ou en rouleau chinois. Nous chutons visuellement en même temps que le narrateur semble chuter dans la mort (il rêve en réalité son suicide). Les couleurs sont très sombres tandis que le film fait défiler empilements de crânes et échafaudages métalliques, au son de cris d'oiseaux menaçants, de frottements métalliques là encore. Le mouvement descendant s'accélère, les hauts murs d'une sorte de colisée antique viennent confiner l'espace de la chute. Une analogie visuelle se produit avec les représentations médiévales de la chute aux enfers de La Divine Comédie de Dante - l'illustration de la Carte de l'Enfer, de Botticelli notamment (vers 1485-vers 1495). La chute d'Alice dans Les Aventures d'Alice au pays des merveilles (1865, Lewis Carroll) est également présente sur un plan associatif, en tant que chute verticale figurant un passage entre réalité et rêve. Le montage est très rapide, permettant à peine de distinguer consciemment les images. La chute s'achève sur un trou creusé dans le sol au fond d'un puits macabre. Une pelle est déposée - c'est sa tombe. Un fondu enchaîné dans ce noir funeste permet le retour des constellations. Le rêve commence.
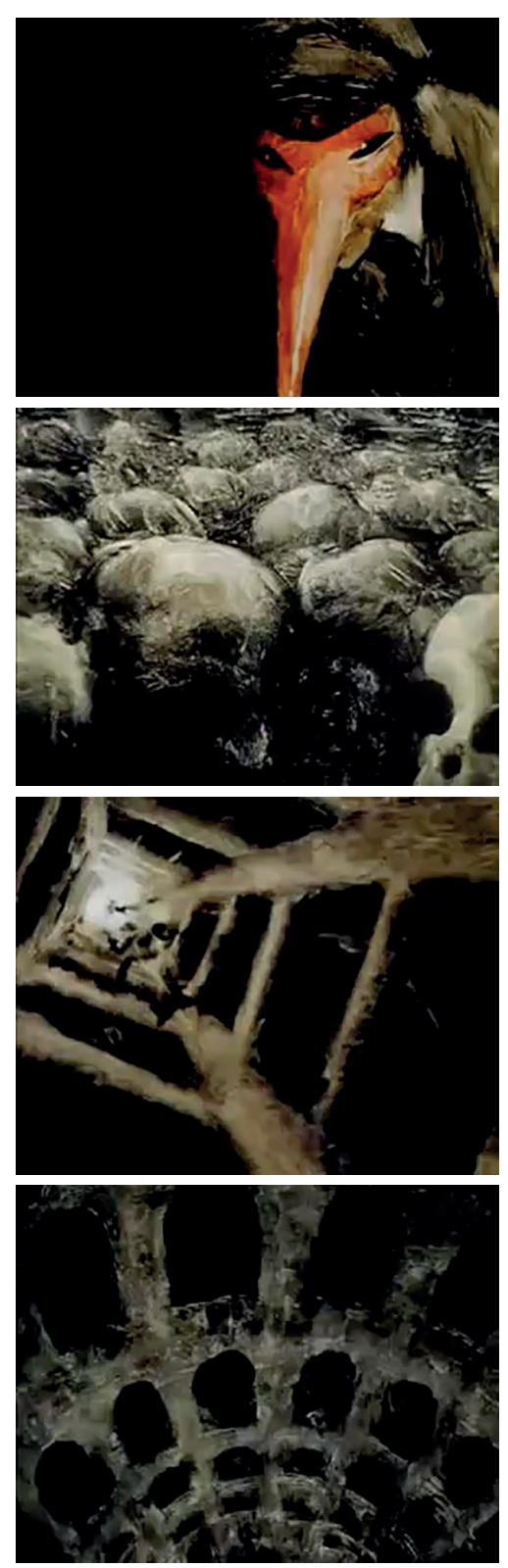

Le Rêve d'un homme ridicule,

Aleksandr Petrov, Studios Panorama, 1993, 4'56, 5’05, 5' 14 et 5'18, captures d'écran 
Cette séquence, marquée par des procédés de saturation visuelle et sonores, est très chargée symboliquement, les images se succèdent en saccades, agissant de manière suggestive sur la perception.

Dans la nouvelle, rien n'est dit explicitement quant à ce que Dostoïevski place symboliquement dans le personnage de son narrateur (dénonciation du Progrès, de la Science, du Rationalisme et du Positivisme européens). Le texte, publié dans son Journal, s'adresse à des lecteurs avertis, connaissant ses positionnements et à même de les y déchiffrer. De la même manière, l'allégorie politique est rendue de manière implicite et suggestive par Petrov dans cette séquence. Ainsi peut-on estimer que le masque symbolise visuellement les espoirs trompeurs de la civilisation; les structures métalliques sombres peuvent être perçues comme des associations faites à l'Occident urbain, ce «royaume de Baal » décrit par Dostoïevski; l'allusion à Dante nous situe également dans cette idée d'un égarement spirituel pavé de péchés dans le chant préliminaire au Purgatoire... Les motifs choisis, issus d'un univers référentiel essentiellement mythologique et biblique, sont ceux de Petrov, mais ils incarnent, matérialisent, figurent précisément la grande métaphore de la nouvelle : la civilisation accompagnant la chute dans le néant.

Petrov utilise des procédés de dessin, de montage, de bruitages personnels et originaux (montage vertical, etc.), lesquels, associés à la représentation d'archétypes culturels permettent la transmission du message dostoïevskien par association symbolique (ici : tromperie [masque]/maladie [peste]/ déclin [chute]/guerre [crânes]/civilisation [colisée]/mort [tombe]...).

Le cinéaste explique être à la recherche de ces associations, parlant « d'électrochocs de souvenirs » faisant irruption dans ses images. Il s'agit pour lui de créer des motifs [obrazy] « à même d'exprimer l'état intérieur du personnage ou de souligner une pensée philosophique $^{54} \gg$.
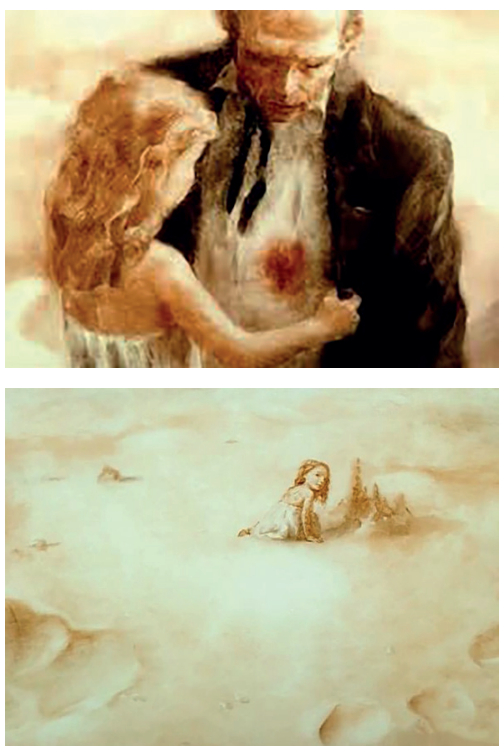

Le Rêve d'un homme ridicule, Aleksandr Petrov, Studios Panorama, 1993, 7’02 et 6'43, captures d'écran 
SLOVO

330 À l'Est de Pixar : le film d'animation russe et soviétique - nº 48/49

Le rêve se poursuit par l'arrivée du narrateur sur l'autre Terre. Sa première rencontre sera avec la petite fille, sur une plage vierge de nouveau monde. D'un mouvement lent, elle vient à lui et soulage de sa main sa blessure au coeur, que l'on voit s'effacer et guérir. Nouvelle insertion symbolique de Petrov, la petite fille construit non pas des châteaux de sable mais des tours rappelant la tour de Babel, symbole, dans la Genèse, de l'orgueil des hommes, ayant voulu atteindre Dieu. La rhétorique
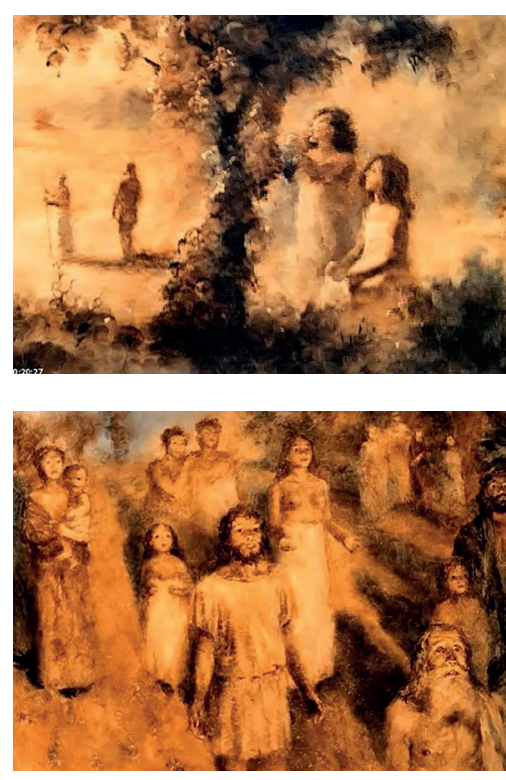

Le Rêve d'un homme ridicule,

Aleksandr Petrov, Studios Panorama, 1993, 10'24 et 10'52, captures d'écran dostoïevskienne, quoiqu'exprimée par une symbolique absente de la nouvelle, est encore là.

Débutent de longues séquences évoquant l'Âge d'or dans son iconographie classique (Pierre-Charles Trémolières et Nicolas Delobel, Léonard de Vinci). Les tonalités de couleur comme la facture choisies incitent à penser que Petrov a voulu rapprocher son dessin des représentations Renaissance et $\mathrm{XVIII}^{\mathrm{e}}$ siècle à la sanguine du mythe. Cet aspect renvoie à nouveau aux analyses bakhtiniennes du texte, que Petrov a sans doute possible lues et étudiées avec précision. Bakhtine a en effet notamment mis en évidence l'importance de l'héritage antique du point de vue du genre chez Dostoïevski (Dostoïevski n'a rien à voir, plaide-t-il longuement, avec ses contemporains du point de vue du genreson œuvre a d'autres origines, d'autres procédés, d'autres fins). La nouvelle conforte cette analyse. Il écrit d'ailleurs à son propos : «D’une façon générale, ce n'est pas l'esprit chrétien mais celui de l'Antiquité qui est mis en avant dans Le Rêve d'un homme ridicule ${ }^{55} \gg$.

Dans la nouvelle, Dostoïevski évoque les archipels grecs, et le film figure cet environnement - un bord de mer paisible, une puissante sensation de lumière, de chaleur, les fleurs et les essaims d'oiseaux. Ce monde semble démesurément chaleureux et bienveillant, les êtres y vivent à peine vêtus, joyeux, heureux. Des hommes accueillent le narrateur. Les oiseaux chantent. Les arbres sont luxuriants, hommes, femmes et enfants évoluent en pagne, dans la plus grande sérénité. 

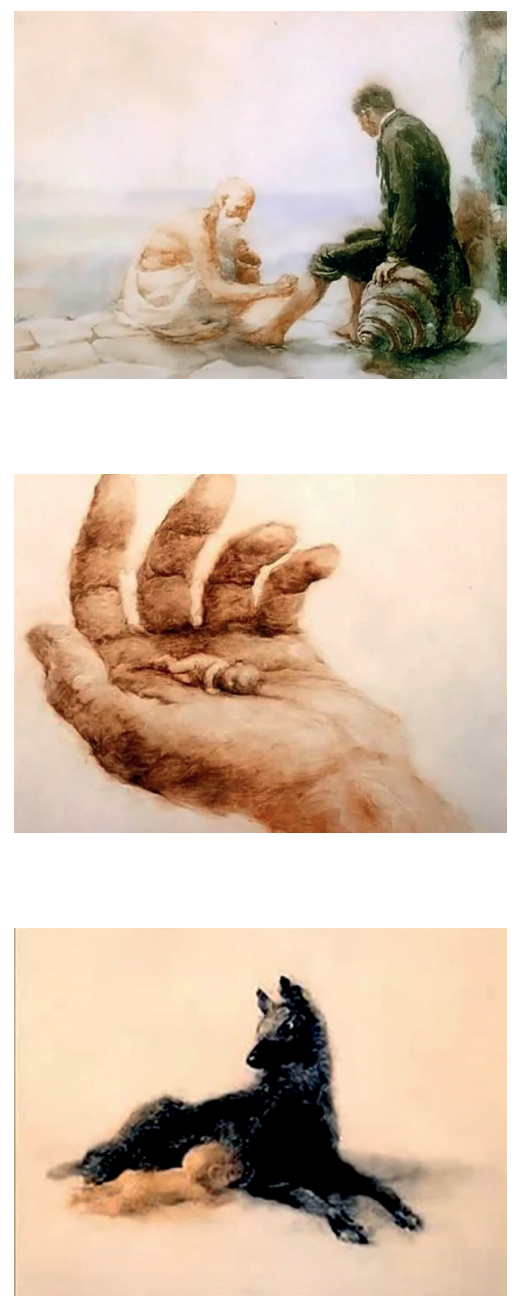

Le Rêve d'un homme ridicule, Aleksandr Petrov, Studios Panorama, $1993,8^{\prime} 12,9^{\prime} 02$ et $10^{\prime} 13$, captures d'écran
Soudain, un vieil homme lave les pieds du narrateur (symbole biblique d'amour et de transformation de la pyramide humaine en un corps; $c f$. le lavement des pieds des Apôtres par Jésus au dernier repas précédant sa Passion). Un chien avenant et gai vient également nous rappeler ce qu'écrit Dostoïevski sur l'union profonde qui unit hommes et animaux.

Comme toujours, les images de Petrov sont ses propres associations (mythe de Babel, allusion au lavement des pieds des apôtres par Jésus...). Toutefois, elles s'inscrivent en communion profonde avec le message dostö̈evskien.

Le procédé de défilement vertical est réutilisé de manière ascendante cette fois-ci, s'achevant par l'anamorphose troublante d'un arbre se transformant en visage de femme. Ces effets visuels de Petrov sont tout à fait originaux. La petite fille dépose dans la main de l'homme un bébé endormi, de la taille d'un pouce. Il se transformera en oiseau: l'idée dostoïevskienne est encore transmise qu'il n'est pas de frontière entre les espèces vivantes. Le bébé s'abreuvera même aux mamelles de la chienne (image déjà présente dans $L a$ Vache)...

Petrov met également un soin particulier à la représentation du soleil, objet d'adoration des hommes de l'autre Terre. Lorsqu'il peint un vieillard s'approchant de l'astre pour fusionner littéralement avec lui, les mots de Dostoïevski («On pouvait 
SLOVO

332 À l'Est de Pixar : le film d'animation russe et soviétique - nº 48/49

penser qu' ils gardaient des contacts avec leurs défunts même après la mort, et que la mort n'interrompait nullement leur union terrestre $\left.{ }^{56} \gg\right)$ sont présents sous forme allégorique : à l'image, un arbre pousse soudain à sa place.

Sur le plan des influences iconographiques, un œil averti reconnaît la peinture de Claude le Lorrain (1600-1682) dès les premières images du film, lequel s'ouvre en clair-obscur sur une bougie vacillante, avançant comme en caméra subjective. Les tours de Babel de l'enfant rappellent en droite ligne celles de Bruegel l'Ancien («La Tour de Babel », 1563). Le film pullule d'une manière générale de références visuelles à la peinture Renaissance et classique. Toutefois, ces présences sont comme intégrées par le dessin de Petrov, nourri à ces écoles picturales. Le cinéaste reconnaît avoir épinglé une image du Lorrain, précisément, pour son travail autour des images de l'Âge d'or. Il s'agit d' «Acis et Galatée » (1657), tableau emblématique du paysage de type classique que Dostoïevski aimait particulièrement ${ }^{57}$. Toutefois, il répugne aux procédés de citations visuelles appuyés et démonstratifs dans l'animation :

Je n'essaie jamais de citer ou de me nourrir de tel ou tel artiste, ou de styliser un film en m'inspirant de tel ou tel peintre ou école. J'ai arrêté, à un certain moment, de me soucier de la forme, de me demander quel devait être le style, à qui cela devait ressembler, ce qu'elles devaient susciter, quelles allusions, est-ce que je fais de l'Avant-garde, ou de la Renaissance, ou je ne sais quoi encore. [...] Lorsque j'ai commencé à faire mes propres films, j'ai oublié que c'était nécessaire, et je dessinais comme je pouvais. Bien sûr, j'essayais d'être fidèle à moi-même, $j$ 'essayais de faire en sorte que ma forme ne soit pas en conflit avec la source littéraire. Mais j'ai arrêté de chercher une forme pour l'exprimer. Je ne prenais pas en particulier Goya pour illustrer Dostoïevski, bien que cela ait pu avoir du sens. Certains remarquent, ça et là, que oui, ici tu as du Goya, là du Bosch, et là encore autre chose. [...] Le film est sur [cet] Âge d'or, et j'ai pensé que si Dostoïevski estimait que Claude le Lorrain correspondait à cet idéal, alors je devais afficher ses peintures. Mais le film ne contient pas une stylisation du Lorrain, pas un paysage, pas une portion de ses travaux qui s'immiscerait. Ce n'est pas que je le fasse exprès, mais j'ai l'impression qu'il n'y a pas d'obligation à tirer tel ou tel

56. Partie IV.

57. Dostoïevski considérait que le Lorrain était le seul artiste parvenu à figurer le sentiment de l'Âge d'or, cette harmonie que l'Humanité avait et qu'elle perdit pour ne plus faire que tendre vers elle, ou s'en éloigner. 
peintre par l'oreille pour, grâce à lui, transmettre telle ou telle idée. J'essaie néanmoins de créer des motifs, des signes, des symboles, des compositions. C'est beaucoup plus intéressant. Le Rêve d'un homme ridicule est un matériau visuel, et tous mes peintres préférés y sont. On peut sûrement y retrouver Rembrandt, voir Goya, Brueghel. Il est clair que tout cela est présent à un certain niveau, mais pas sous forme de citations ${ }^{58}$.

Dans l'ultime partie du rêve, consacrée à l'avancée dans le chaos, la musique minimaliste de Raskatov est rehaussée par des tonalités hongroises: celles de Béla Bartók, György Ligeti. On pense au Grand Macabre (1977), notamment, dans ce contexte particulier. Le ton énigmatique puis angoissant que la musique donnait au film à son début se transforme en danse terrifiante.

Comme dit précédemment, le début du chaos est symbolisé dans le film par un masque exprimant la duperie. Le narrateur s'est revêtu d'un fichu de femme et s'est masqué. Il s'est en somme déguisé en femme et s'approche d'une adolescente (en qui l'on devine la petite fille, qui a grandi), la poitrine découverte, qui lui sourit avec toute la tendresse et l'innocence du monde. Soudain, le narrateur enlève le masque et rit de sa supercherie : il se moque et offense la confiance de la jeune femme. On retrouve ici le thème de l'offense à la Terre-Mère évoqué par Motchoulski dans son analyse de la nouvelle. Le doute s'immisce pour la première fois dans les yeux de la jeune femme, la méfiance, la peur. C'est alors que l'araignée vient s'immiscer le long du bras du narrateur, annonce de l'arrivée du Mal. Le chien, si bon, se met à grogner, se fait menaçant. Et la femme devient, en quelques plans, tentatrice et lubrique. «Dans le paradis sur terre, le mal pénètre sous l'aspect d'une lubricité meurtrière », écrivait Motchoulski.

Le Rêve d'un homme ridicule, Aleksandr Petrov, Studios Panorama, 1993, de 12'18 à 12 '25, captures d'écran

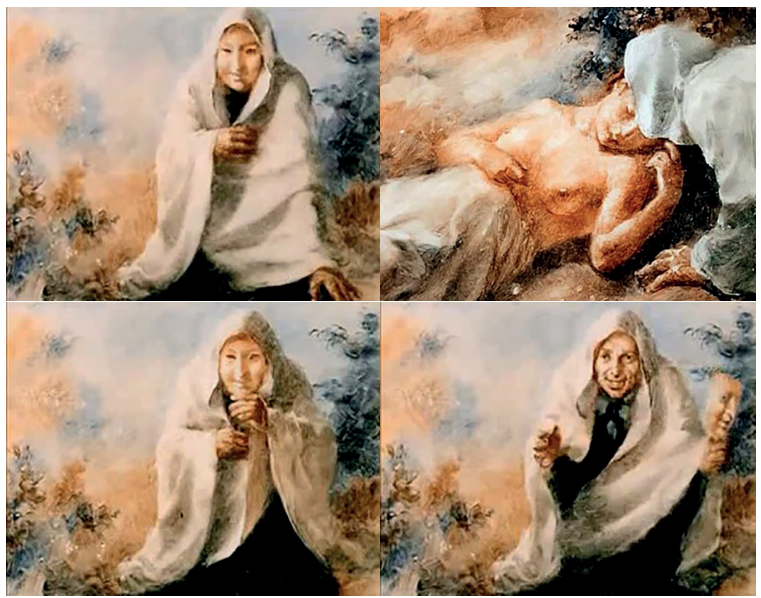


SLOVO

334 À l'Est de Pixar : le film d'animation russe et soviétique - nº 48/49

Ce second masque dans le film est le point départ de l'enchaînement des maux qui vont déferler sur cette terre. La lubricité de la jeune femme provoquera la jalousie des hommes, entraînant à son tour vengeance, cruauté, guerre et destructions. Petrov insuffle à son film un souffle puissant dans ces scènes décrivant l'enchaînement fatal d'autodestruction de l'homme.

Les choix rythmiques, musicaux, la symbolique visuelle mélange de scènes païennes et de carnaval déchaîné font l'effet d'une transe, d'une entrée irréversible dans le chaos.

Jérôme Bosch (1450-1516) est effectivement très présent, à l'état de réminiscence pour le spectateur. Reviennent également en mémoire les images d'Andreï Roublev (1966) d'Andreï Tarkovski, en particulier les scènes de nuits païennes et de débridement des corps. Elena Dolgopiat évoque l'importance de l'univers païen et mystique chez Petrov, dont les films sont parsemés d'esprits, de sirènes, et de voix. «Son animation est dans sa nature même un culte païen », écrit-elle. Pour elle, l'un des aspects les plus forts de ce culte est le sacrifice, que l'on retrouve dans La Vache et dans Le Rêve d'un homme ridicule (au sein duquel la petite fille est une image sacrificielle).

Tout au long du film, les scènes de chaos abondent en références culturelles mythologiques, bibliques ou archétypales: danses collectives/présence $\mathrm{du}$ feu/ hommes construisant des murs/lapidations/homme affublé de cornes, rappelant le Minotaure ou le Diable/pleurs d'enfants/nuit... Les détenteurs de la science et de la connaissance prêchent sur des promontoires humains (empilements d'hommes et de femmes à leur autel). Ces séquences se ponctuent par des scènes de folie et de débauche : fous, culs de jatte, luxure... avec pour finalité inévitable la Mort et la destruction du groupe.

Tout le travail de Petrov consiste, comme il le dit, à créer motifs, signes et symboles capables d'exprimer par d'autres voies la pensée dostoïevskienne.
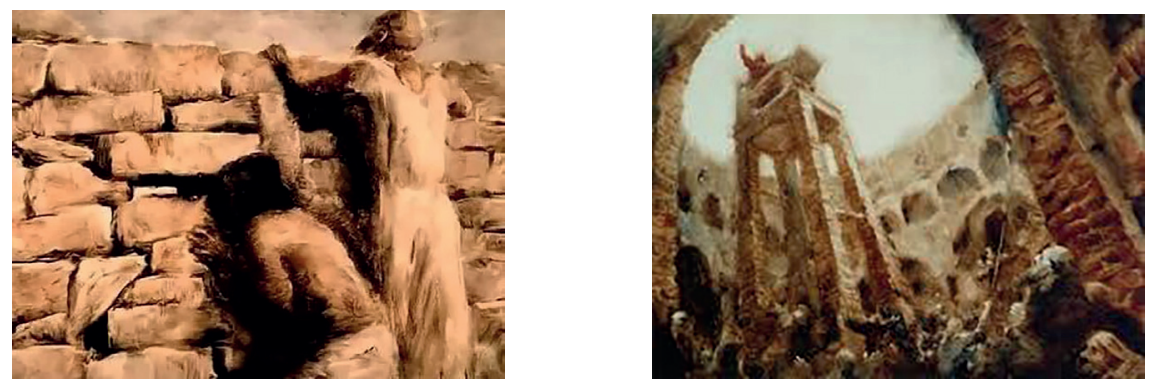

Le Rêve d'un homme ridicule, Aleksandr Petrov, Studios Panorama, 1993, 16'47 et 15'03 puis (page de droite) 16'20 et 17’43, captures d'écran 

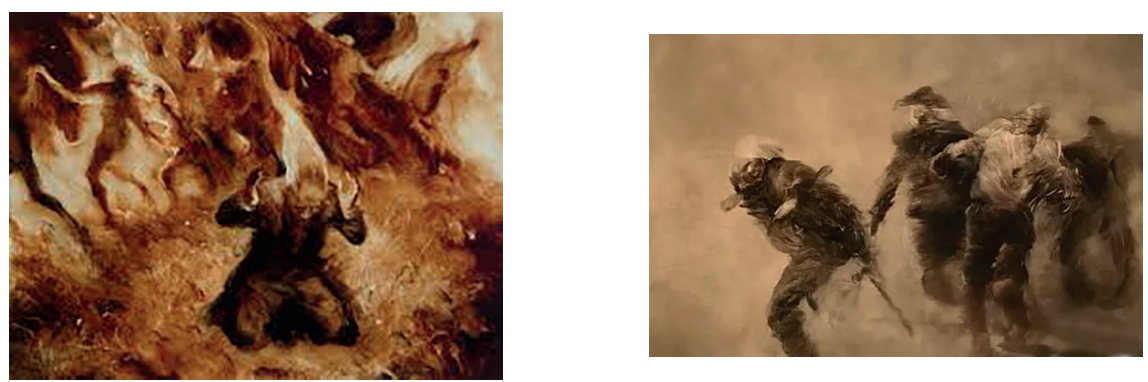

Dans La Poétique de Dostoïevski, nous l'avons dit, Bakhtine explique combien l'œuvre de Dostö̈evski ressort d'après lui profondément de l'héritage antique. Il précise son analyse par de longs développements consacrés au genre antique de la satire «ménippée ». La ménippée, rappelle-t-il, s'apparente à la fin de l'Antiquité classique et pendant la période hellénistique à un type de littérature spécifique, « mêlant le plaisant au sérieux ». S'opposant aux genres sérieux qu'étaient l'épopée, la tragédie, l'histoire, la rhétorique classique, elle était fortement inspirée du folklore carnavalesque, basé sur le renversement. Cette présence d'une vision carnavalesque du monde plaçait l'image et le mot dans un rapport particulier avec la réalité, dans une sorte de « relativité joyeuse » ayant pour particularité l'atténuation d'une rhétorique unilatérale, du rationalisme, de l'aspect monique et dogmatique ${ }^{59}$.

Voici sous une forme paraphrastique quelques éléments typiques de la Ménippée, selon lui :

La Ménippée n'est liée à aucune exigence de vraisemblance extérieure, c'est un genre libre en fait d'imaginaire et de fantastique, où des fantasmagories débridées sont parfois justifiées par un but purement idéal et philosophique. Son symbolisme parfois mystique se combine à un naturalisme des bas-fonds outrancier et grossier.

Bakhtine parle également de la représentation d' « états psychiques anormaux », de $\ll$ conduites excentriques $»$, de $\ll$ contrastes violents ${ }^{60} \ldots$

Il est impossible que Petrov ait pu ignorer ces aspects d'analyse en amont de sa conception du film. Il s'en inspire même dans une dimension maximale.

Lorsqu'il crée des images pour son propre transfert poétique de ce texte vers les moyens expressifs de l'animation, Petrov se souvient de cette parenté, et toute sa figuration du rêve ressort de la culture carnavalesque. Non pas joyeuse, mais lugubre

59. BAKHTINe, 1998, p. 161.

60.Ibid., p. 211-219. 
SLOVO

336 À l'Est de Pixar : le film d'animation russe et soviétique - nº 48/49

et sombre, les séquences correspondant au chaos chez Petrov rappellant carnaval, transes, messes. Autant d'éléments de culture carnavalesque très présents et en harmonie profonde avec le sens de l'œuvre. Aussi ne sommes-nous pas devant une illustration du texte, mais face à son extrapolation, en lien étroit avec lui.

Nulle fantasmagorie débridée dans la nouvelle elle-même, de même que l'aspect fantastique se limite au procédé du voyage imaginaire. Les aspects mystiques sont également peu présents de manière explicite, de même que les conduites excentriques (exception faite du fameux capitaine) ou l'évocation des bas-fonds: Petrov les crée et les insuffle de toute pièce, notamment dans le passage de l'accélération du chaos. Dans La Poétique de Dostoïevski, Bakhtine écrit sur la nouvelle: «L'argumentation méthodique tant soit peu développée est totalement absente. C'est un exemple frappant de l'aptitude exceptionnelle de Dostö̈evski [...] à voir et à sentir artistiquement l'idée. Nous avons affaire ici à une authentique peinture de l'idée. » Il souligne le grand laconisme du texte, typique de la Ménippée. Petrov, précisément, figure les silences du texte, puisant dans les racines les plus profondes de l'univers symbolique et référentiel dostoïevskien.

Le narrateur se retrouve à la fin du film avec dans ses mains une figurine le

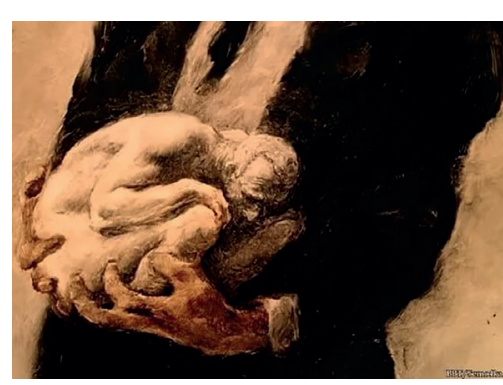

Le Rêve d'un homme ridicule,

Aleksandr Petrov, Studios Panorama, 1993, 18’07, capture d'écran représentant lui-même, recroquevillé tel une chimère, monstrueuse et repentante. Cette terre va se détruire. Le moteur du chaos est en marche, chaos qu'il a déclenché mais ne peut plus arrêter.

Les images effectuent un retour sur le motif de l'étoile initiale, qui avait donné au narrateur le signal de la nécessité de son acte dans la nouvelle, qui figure l'Autre Terre dans le film. Le spectateur est ramené à la sensation du tangage du train, à ses bruits, sa cadence, à notre Terre.

Le visage de la petite fille apparaît, un fichu sur la tête. La séquence finale nous montre le narrateur marchant avec elle, sa petite main dans la sienne, ils sont près du réverbère de leur rencontre. Il l'a retrouvée.

\section{Conclusion}

Quand j'étais sur le projet Dostoïevski, j'avais l'impression que j'essayais de trouver des solutions aux mêmes questions que celles que posait Dostö̈evski, que j'essayais de les vivre et de les ressentir à mon tour. J'essayais de les mettre à l'épreuve de moi-même. 
J'avais l'impression que quand j'aurais fait ce film, je deviendrais tout simplement et définitivement un sage, et que je n'aurais plus rien à faire, que le travail accompli viendrait s'ajouter à la somme de mes connaissances, à mon niveau de sagesse. Mais c'était là une erreur puérile. J'ai sincèrement essayé de ressentir et de faire rejaillir cette tension de la pensée que Dostoïevski insuffle dans son récit. J'ai essayé de créer avec honnêteté une œuvre proche et juste dans l'intonation, dans l'intensité, mais je ne peux pas dire que j'aie répondu à toutes les questions. En fait, je n'ai sûrement répondu à rien. J'étais simplement heureux de l'avoir fait, bien que cela ait été harassant et difficile; j'étais toujours à la frontière de l'échec, du découragement : dans quel pétrin est-ce que tu t'es fichu ? Pourtant le film s'est fait ${ }^{61}$.

Petrov ne nie pas que le processus de création du film a également eu une grande influence sur lui sur un plan personnel. Il savait combien Dostö̈evski serait complexe à adapter mais reconnaît qu'il ne se risquerait plus aujourd'hui à investir un projet présentant de tels enjeux moraux et spirituels.

Sur un plan concret, il explique avoir délibérément abandonné certains aspects de la nouvelle: «Je ne suis pas Dostoïevski [...]. J'ai essayé de me plonger dans les profondeurs [de cette œuvre], mais j'ai compris que je n'avais pas assez... la foi peut être, celle qu'il avait, ou la force qu'il avait. Alors j'ai décidé de laisser de côté certaines choses, de ne pas m'y plonger ${ }^{62}$. »

Le cinéaste n'exprime nulle part explicitement quels sont les thèmes si difficiles pour lui qu'il a préféré les écarter. Celui de l'indifférence envers la honte nous semble peut-être éludé. C'est le motif essentiel du début de la nouvelle (l'idée de ce « tout m'est égal », de l'idéalisme subjectif), alors qu'il renvoie en droite ligne à la « confession de Stavroguine » et donc à un thème central de l'auteur (ce « cœur obscur » dont parle Markowicz).

Le thème central de la nouvelle, la liberté d'agir de l'homme, de créer le Bien comme le Mal est en revanche hautement exprimé, tout comme l'idée de responsabilité, le thème dostoïevskien de la renaissance au gré des douleurs et des conflits spirituels, celui de la bonté intrinsèque de l'Homme et de la possibilité d'une fraternité humaine.

61. Petrov, 2001.

62. MARgOLINA, 2002. 
SLOVO

338 À l'Est de Pixar : le film d'animation russe et soviétique - nº 48/49

L'élément le plus marquant du film sur le plan du transfert narratif reste la présence des scènes païennes et la puissance esthétique déployée dans sa description du chaos (soit la figuration de l'allégorie avec unissant son narrateur à l'Europe et la civilisation).

Comme le rappelle Julia Kristeva en introduction à La Poétique de Dostoïevski, le carnaval dans la tradition ménipéenne «symbolise le monde moderne ${ }^{63}$ ». Il est absolument clair que Petrov a lu Bakhtine est s'est fortement inspiré de ses analyses liées à la culture carnavalesque. Cette compréhension profonde du système esthétique dostoïevskien lui permet d'emprunter à son tour à cet univers afin d'exprimer cette idée de dégénérescence moderne dans une grande communauté d'esprit avec l'auteur. Ainsi, le film n'est pas une actualisation du récit vouée à dénoncer, un siècle plus tard, les maux décrits par Dostoïevski (on ne prête d'ailleurs à Petrov aucun anti-occidentalisme notoire). Le film vient matérialiser sur un plan référentiel, iconographique et sensoriel la perception intérieure du cinéaste. Il est une figuration, une extrapolation poétique du texte par les procédés de l'animation.

Considéré par le critique A. Orlov comme «le plus profond des films de Petrov », Le Rêve d'un homme ridicule est surtout une œuvre déployant un monde imaginaire foisonnant, mystique et troublant, où le texte concis et laconique de Dostoïevski devient le ferment d'une inventivité visuelle et d'une mise en scène magistrales.

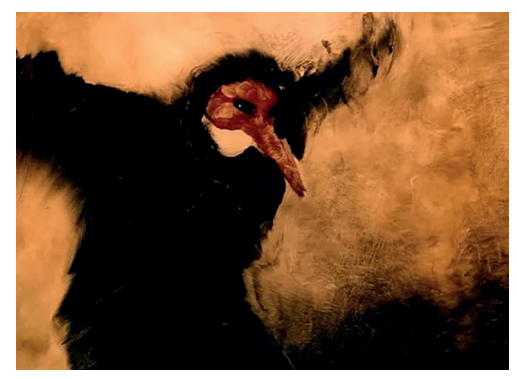

Le Rêve d'un homme ridicule, Aleksandr Petrov, Studios Panorama, 1993, 13'57, capture d'écran 


\section{Bibliographie-Filmographie}

Bakhtine Mihal M., 1998, La poétique de Dostoiëvski, trad. Kolitcheff Isabelle, Éd. du Seuil (coll. Points Essais), Paris.

Čuev Nikolaj, 2006, Mul'tiplikacija, moja ljubov'[Animation, mon amour].

Dostonvski Fédor, 2016, Le Rêve d'un homme ridicule: un récit fantastique, trad. Markowicz André, Actes Sud, Arles.

Dostoïtevski Fédor, 2005, CEuvres romanesques: 1869-1874, trad. Markowicz André, Actes Sud (coll. Thesaurus), Arles.

Ermilova Nonna \& Voronova Anastasija, 2003, «Animacionnoe kino povyšennoj duxovnosti» [D’un cinéma d'animation à spiritualité élevée], http://animator.ru/articles/article.phtml?id=21 (lien actif en décembre 2017).

Estève Michel \& Labarrère AndréZ. (dir.), 2017, Dostö̈evski à l'écran, Éditions Charles Corlet (coll. CinémAction), Condé-sur-Noireau.

Margolina Irina, 2002, Le Monde de l'animation et l'animation du monde, [Mir animacii ili animacija mira].

Motchoulski Constantin, 1963, Dostö̈evski : l'homme et l'OEuvre, trad. Welter Gustav, Payot, Paris.

Petrov Aleksandr, 2001, «Ja ne mogu skazat', čto stanovljus' umnee s každym fil'mom», [Je ne peux pas dire que chacun de mes films me rende plus intelligent], propos recueilli par Dolgopiat Elena, in Kinovedčeskie zapiski, http://www.kinozapiski.ru/ru/article/sendvalues/804/ (lien actif en décembre 2017).

Šatina Z \& Antropov V., 2005, Xudožestvennye fil'my. Katalog literaturnyx èkranizacij/900 imën (1908-2005) [Les Films de fiction. Catalogue des adaptations littéraires. 900 noms (1908-2005)], Moscou, Éditions Golden B/Gosfilmofond. 
SLOVO

340 À l'Est de Pixar : le film d'animation russe et soviétique - nº 48/49

Résumé : en 1992, Aleksandr Petrov, étoile montante de l'animation russe, réalisait Le Rêve d'un homme ridicule, d'après la nouvelle de Dostoïevski (1877). Le choix de cette œuvre extrêmement complexe, sorte de synthèse de la pensée religieuse de Dostoïevski, paraît répondre à une nécessité intérieure pour le cinéaste. L'œuvre qui en ressort, court-métrage de vingt minutes, est un film d'une puissance narrative exceptionnelle, frappant par une communauté d'esprit et un niveau d'intimité troublants avec l'auteur. D'une part, Petrov s'adonne au nécessaire travail de condensation du texte, redéployé narrativement à travers différents procédés suggestifs profondément imprégnés de l'univers diégétique de Dostö̈evski (bruitages, musique, rythme, couleurs...). Surtout, la dimension fantastique et la présence centrale du rêve dans le texte en font un matériau idéal pour un cinéaste très inspiré par les notions de glissement (d'une réalité à une autre), de passages et de métamorphoses.

Mots-clefs : Adaptation, peinture sur verre, Dostoïevski, Le Rêve d'un homme ridicule, le rêve au cinéma, sémiotique du cinéma, transcodage filmique.

Abstract: it was in 1992 that Aleksandr Petrov, a budding star in Russian animated film, directed The Dream of a Ridiculous Man, based on Dostoevsky's short story of the same name, first published in 1877. Choosing this extremely complex work, which engages with all Dostoevsky's views on religion, seemed to correspond to some deep inner need on the part of the filmmaker. The resulting work, a 20-minute short, is an extremely powerful narrative that testifies to the striking and almost uncanny affinity that exists between Dostoevsky \& Petrov - a true meeting of minds. On the one hand Petrov throws himself into condensing and redeploying the original text, using various evocative means (such as noise, music, rhythm \& colour) imbued with Dostoevsky's narrative world. But above all it's the element of fantasy and the central presence of the dream in the text that stands out, providing an ideal subject matter for a filmaker deeply inspired by the notions of slipping (from one reality to another), passages and metamorphoses.

Keywords: Adaptation, Paint-on-glass animation, Dostoyevsky, The Dream of a ridiculous man, dream in film, film semiotics.

Абстракт: в 1992 году Александр Петров, восходящал звезда российского анимачионного кинематографа, создаёт Сон смешного человека по одноимённому рассказу Ф.М. Аостоевского (1877). Выцбор этого крайне сложного произведения, некого синтеза религиозной мьссли Аостоевского, словно основан на внутренней потребности режиссёра. Получившаяся работа, двадиатиминутньй короткометражньий фильм, обладает невероятной повествовательной силой и поражает единением мысли и степенью близости 
с автором. С одной стороны, Петров выполняет необходимую работу по сжатию текста, который он изобразительно перестраивает через различные суггестивные приёмы (шумовое оформление, музыка, ритм, ивета...), глубоко пропитанные диегетическим миром Аостоевского. С другой стороны, фантастический аспект и центральное место сна в тексте представляют идеальньии материал для режиссёра, которого особо вдохновляют понятия перемещения (из одной реальности в другую), перехода и метаморфозы.

Ключевье слова: Живопись по стеклу, ожившая живопись, Аостоевский, Сон смешного человека, сон в кино, семиотика кино. 